\title{
Elementos para una reflexión sobre la Administración General del Estado
}

\author{
Javier Valero Iglesias \\ Administrador Civil del Estado \\ Javier.Valero@meh.es
}

\begin{abstract}
Resumen
En el presente trabajo se analiza la dimensión cuantitativa que tiene que tiene la AGE en lo que se refiere a sus efectivos y al volumen del gasto público en relación al PIB nacional y se comparan las cifras con los países de la Unión Europea. En segundo lugar se describe la percepción que los ciudadanos españoles tienen de la AGE y de los servicios públicos según los estudios realizados por el Centro de Investigaciones Sociológicas. El tercer capítulo contiene una panorámica de los procesos de reforma y modernización de la Administración General del Estado llevados a cabo en España desde el restablecimiento de la democracia en 1977. Por último, en el capítulo de conclusiones se mencionan las más importantes, entre las que cabe destacar que ni la Administración ni el gasto público en nuestro país están sobredimensionados; que es preciso llevar a cabo una reflexión acerca de la necesidad de incrementar el número de funcionarios dedicados a tareas de carácter directivo y de contenido técnico complejo; y que la plena implantación de la Administración Electrónica debe ser la apuesta principal para el próximo quinquenio.
\end{abstract}

Palabras clave Administración Pública, Administración General del Estado, Recursos humanos de la AGE, gasto público, opinión de los ciudadanos sobre la Administración, reforma de la Administración, modernización de la Administración.

\section{Factors for a reflection about State Public Administration}

\begin{abstract}
Firsth Civil servants numerical rates related to the Gross Domestic Product in Public Administration in Spain are presented in the paper compared to other Member States of the European Union. Secondly paper also includes citizenship opinion towards Public Administration services provided by the Government based on surveys carried out by the Sociology and Research National Centre. The third chapter provides an overview of the reforms implemented in Spain from the democracy in 1977 until now. Main conclusions are neither civil servants numerical rates nor Public Expenditure in Government are oversized; the need to increase the qualified and technical staff; and finally to implement the E-Government during next five years.
\end{abstract}

Key words

Public Aministration, Spanish State Administration, Human Resources in State Administration, Government expenditure, Public image of State Administration, Public Management Reform. 


\section{LA DIMENSIÓN DE LA ADMINISTRACIÓN GENERAL DEL ESTADO EN EL CONJUNTO DE LAS ADMINISTRACIONES PÚBLICAS}

\section{Efectivos de la Administración Pública Estatal y de las demás Administraciones Públicas}

Cuando se trata de la Administración General del Estado y de los cambios que ésta debe acometer para dar satisfacción a las misiones que tiene planteadas a fin de cubrir las necesidades de los ciudadanos, es imprescindible, dado el contexto de modelo de Estado descentralizado política y administrativamente en que nos encontramos, fijar de la manera más clara posible las dimensiones de la misma y poner los datos en relación con el resto de las administraciones públicas.

Para establecer esa dimensión utilizaremos los datos del Registro Central de Personal dependiente del Ministerio de Política Territorial y de Administración Pública (y durante décadas, anteriormente, del Ministerio para las Administraciones Públicas), publicados periódicamente en el Boletín Estadístico del Personal al Servicio de las Administraciones Públicas. En nuestra opinión se trata de la fuente más fiable ya que está basada en datos proporcionados directamente por las propias Administraciones e instituciones que no han sido obtenidos a través de encuestas u otros métodos indirectos.

A fecha 1 de julio de 2009, últimos datos consolidados publicados por el Registro Central de Personal en el mencionado Boletín Estadístico de que disponíamos al comenzar a elaborar este trabajo, la Administración Pública Estatal agrupaba un total de 583.447 personas que incluían las 239.865 de ministerios, organismos autónomos y áreas vinculadas a los mismos, a la docencia no universitaria, a los centros penitenciarios, a la administración de la Seguridad Social, al Patrimonio Nacional, a las agencias estatales y a las instituciones sanitarias. A todos ellos se sumaban, en primer lugar, los 135.950 miembros de las Fuerzas y Cuerpos de la Seguridad del Estado (76.643 guardias civiles y 59.307 policías nacionales) y 23.658 miembros de la Administración de Justicia, los 127.373 miembros de las Fuerzas Armadas y, finalmente, los 56.601 de las entidades públicas empresariales. El cuadro siguiente distribuye los efectivos proporcionando una visión de conjunto:

\section{Efectivos de la Administración Pública Estatal}

\begin{tabular}{|l|c|}
\hline * Administración General & 239.865 \\
\hline - Ministerios,OO.AA. y Áreas vinculadas & 233.995 \\
\hline - Ministerios y OO.AA. & 133.813 \\
\hline - Docencia no universitaria & 7.208 \\
\hline - Centros Penitenciarios & 21.839 \\
\hline - Admón. Seguridad Social & 30.237 \\
\hline - Patrimonio Nacional & 1.435 \\
\hline - Agencia Estatal Admón. Tributaria & 29.463 \\
\hline
\end{tabular}


Efectivos de la Administración Pública Estatal (Cont.)

\begin{tabular}{|l|c|}
\hline • Agencias Estatales & 14.256 \\
\hline$\bullet$ Instituciones Sanitarias S. Social & 1.614 \\
\hline * FF. y CC. Seguridad del Estado & 135.950 \\
\hline * Fuerzas Armadas & 127.373 \\
\hline * Administración de Justicia & 23.658 \\
\hline * Entidades Públicas Empresariales & 56.601 \\
\hline TOTAL ADMINISTRACIÓN PÚBLICA ESTATAL & $583.447\left(^{*}\right)$ \\
\hline
\end{tabular}

(*) No se incluye el personal al servicio de la Sociedad Estatal Correos y Telégrafos SA por no tener la consideración de Administración Pública, pero es conveniente hacer constar que, paradójicamente por tratarse de una empresa, de sus 57.891 efectivos 27.487 conservan la condición de funcionarios.

Por lo que se refiere a las Comunidades Autónomas, a la misma fecha, 1 de julio de 2009, el personal a su servicio sumaba una cifra de efectivos de 1.345.577. De ellos, 1.283.041 pertenecían a las consejerías y sus organismos autónomos, a la docencia no universitaria y a las instituciones sanitarias del Sistema Nacional de Salud. Había que agregar las 38.710 personas integradas en la Administración de Justicia y los 23.826 efectivos de sus Fuerzas de Seguridad, según se refleja en el cuadro siguiente:

\begin{tabular}{|l|c|}
\hline * Administración General & 1.283 .041 \\
\hline$\bullet$ Consejerías y OO.AA. & 252.265 \\
\hline$\bullet$ Docencia no universitaria & 539.669 \\
\hline$\bullet$ Instituciones Sanitarias S. N.S. & 491.107 \\
\hline * Administración de Justicia & 38.710 \\
\hline * Fuerzas de Seguridad & 23.826 \\
\hline TOTAL COMUNIDADES AUTÓNOMAS & 1.345 .577 \\
\hline
\end{tabular}

Por su parte, los efectivos de la Administración Local, a 1 de julio de 2009, alcanzaban la cifra de 627.092 personas, de las cuales 550.714 pertenecían a los Ayuntamientos y 76.378 a Diputaciones, Cabildos y Consejos insulares, como se recoge a continuación:

\begin{tabular}{|l|c|}
\hline$*$ Ayuntamientos & 550.714 \\
\hline * Diputaciones, Cabildos y Consejos & 76.378 \\
\hline TOTAL ADMINISTRACIÓN LOCAL & 627.092 \\
\hline
\end{tabular}

Queda fuera de este catálogo de efectivos, por la autonomía de que gozan las Universidades que no están integradas en ninguna de las Administraciones Públicas, el personal integrado en el ámbito docente universitario (102.895 personas)'.

1 Esta cifra no constituye la totalidad de los efectivos de las Universidades, habría que añadir los contratados laborales, que no están inscritos en el Registro Central de Personal, cuyo número no conocemos. 
La primera reflexión a efectuar concierne a la distribución del modelo resultante del proceso de desconcentración política y administrativa que se ha llevado a cabo en España desde la aprobación de la Constitución de 1978. Las Comunidades Autónomas suponen el 52,6 por ciento del total del personal de las Administraciones Públicas, los organismos de la Administración Local agrupan un 24,5 por ciento y el ya residual 22,8 por ciento corresponde a la Administración General del Estado como se muestra en el siguiente gráfico:

Distribución de efectivos entre las Administraciones Públicas

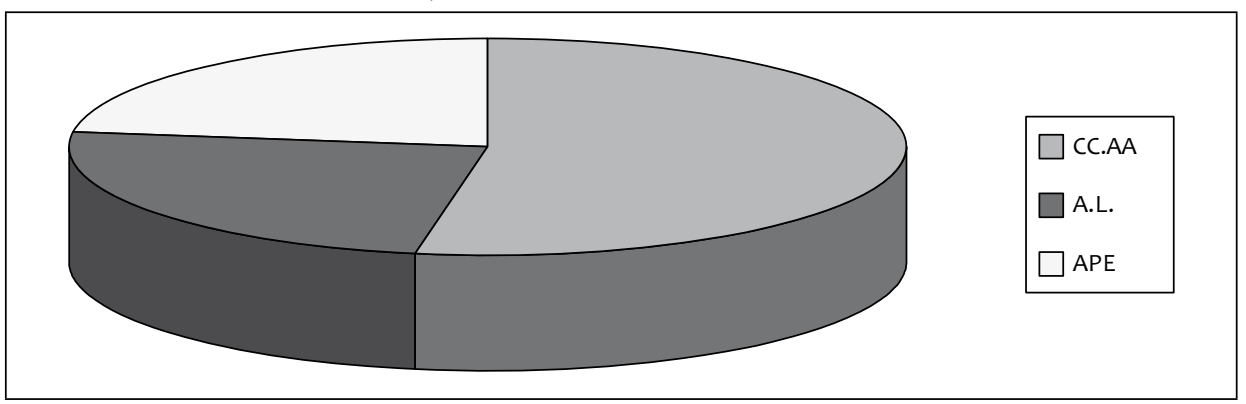

Fuente: Boletín Estadístico del Personal al Servicio de las Administraciones Públicas.

No debemos tener ningún reparo en calificar de espectacular la transformación de la realidad que nuestro país ha experimentado en este ámbito. En 1982, la Administración Pública Estatal representaba el 82 por ciento del empleo público (hoy el 22,8 por ciento), las Comunidades Autónomas el 3,8 por ciento (hoy el 52,6 por ciento) y la Administración Local un 14,4 por ciento (hoy un 24,5). En veinticinco años España, partiendo de un Estado fuertemente centralizado, ha llevado a cabo un proceso de redistribución del poder territorial absolutamente inédito, desconocido en los demás países, si bien no se puede negar que esa rapidez ha implicado la aparición de efectos secundarios negativos como son un incremento notable del gasto público (más allá del aumento ocasionado a la prestación de nuevos servicios públicos y a la satisfacción de necesidades sociales tradicionales o nuevas surgidas como consecuencia del desarrollo del Estado del Bienestar), la aparición de duplicidades en la gestión, la creación de órganos en la administración autonómica a imagen y semejanza de los existentes en la Administración General del Estado dotados de escaso contenido², la permanencia, como contrapartida ineficiente, en la Administración General del Estado de estructuras administrativas de contenido cuestionable que, para justificar su existencia, paulatinamente han generado nuevas actividades anteriormente no realizadas y, en general, unos ratios de eficacia y eficiencia (en aquellas organizaciones donde hay objetivos expresamente establecidos y evaluados) manifiestamente mejorables.

2 A título de ejemplo podemos señalar que hasta diciembre de 2009, según datos del Ministerio 28 de Asuntos Exteriores y Cooperación, las Comunidades 
Una segunda reflexión resulta imprescindible al presentar los datos globales concernientes al empleo público en España, aunque sea marginal al objeto de este trabajo, ya que nos encontramos en una situación de importante déficit público nacional en un contexto de crisis económica global en el que las llamadas a la acción sobre este colectivo, que resultan inevitables en las condiciones actuales, en ocasiones tienen escaso fundamento cuando no son claramente contradictorias con la realidad que los datos ofrecen. Nos referimos a la proporcionalidad existente entre empleados públicos y población española.

España dispone, según la cifra proporcionada por el Boletín Estadístico del Personal al Servicio de las Administraciones Públicas, de un total de 2.659.010 ${ }^{3}$ empleados al servicio de las Administraciones Públicas para un total de población ligeramente superior a los 46.000.000 de habitantes, lo que establece una proporción de un empleado público por cada 17,3 habitantes. Francia, un país de similares características a nosotros, pero con una potencia económica y un desarrollo del Estado del Bienestar superiores tiene una ratio de un empleado público por cada 12,2 habitantes.

En términos de ratio Empleado público/Población activa la desviación es mucho más importante en perjuicio para nuestro país con respecto, por ejemplo, a los avanzados países escandinavos.

Porcentaje empleados públicos/población activa $\left(^{*}\right)$

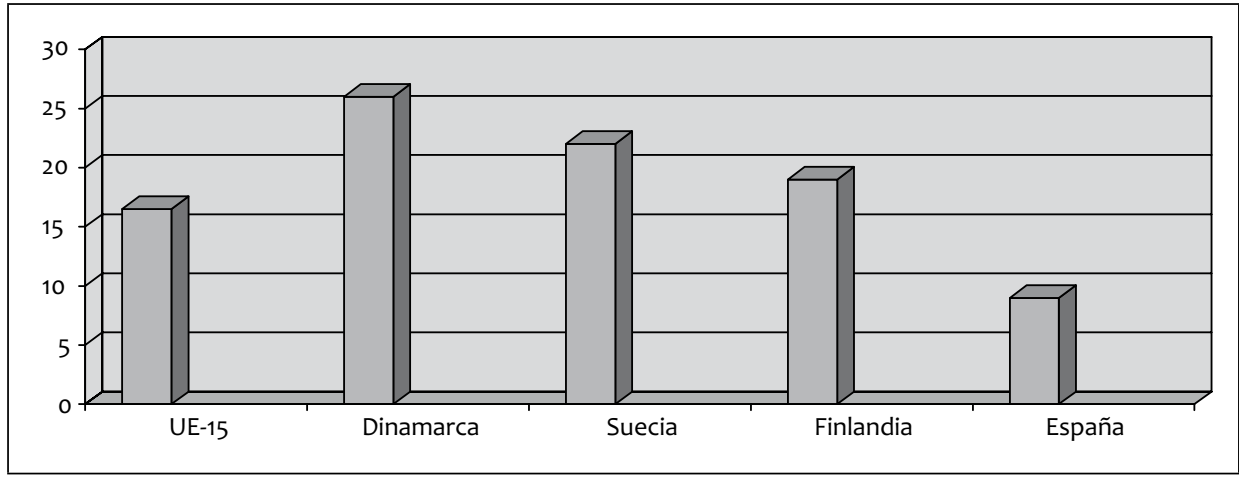

(*) Fuente: Vicenç Navarro, catedrático de Políticas Públicas de la Universidad Pompeu Fabra. Observatorio Social de España.

Adicionalmente hay que señalar que cuando se habla de empleados públicos no podemos tener como referencia solamente al funcionario weberiano decimonónico o de principios del siglo XX sino a los prestadores de servicios del Estado del Bienes-

3 Esta cifra es ligeramente superior a la que ofrece la suma de los parciales presentados anteriormente ya que incluye a colectivos que no forman parte de las Administraciones Públicas como por ejemplo las Universidades (102.894 empleados, tanto docentes como no docentes). 
tar. Así, hay que señalar que en España entre esos 2.659.010 empleados públicos figuran 170.000 miembros de Fuerzas y Cuerpos de seguridad pública, 547.000 profesionales de la enseñanza no universitaria, 491.000 profesionales de las instituciones del Sistema Nacional de Salud, 103.000 docentes y empleados de las universidades y 60.000 de la Administración de Justicia.

\section{Referencia al gasto público}

Quiere ello decir que cuando en el contexto de la acción frente a la crisis económica global y de reducción del déficit público o simplemente desde posiciones de neoliberalismo económico se aboga por reducir el número de empleados públicos, por reducir la administración o por tener "menos Estado" hay que detallar a continuación, si se desea ser riguroso, a que aspectos del Estado del bienestar se está dispuesto a renunciar, si a determinados servicios sanitarios públicos, o a la enseñanza pública o a la gestión del sistemas de pensiones públicas o a reducir el número de agentes encargados de velar por la seguridad ciudadana, etc. etc. ya que, de acuerdo con el documento "Presentación del Proyecto de Presupuestos Generales del Estado para 2010" elaborado por el Ministerio de Economía y Hacienda, el gasto social (pensiones, vivienda, desempleo... ) previsto para el ejercicio representaba el 51,6 del total y un 6,2 \% del gasto estaba destinado a los servicios públicos básicos (justicia, defensa y seguridad). Y hay que tener en cuenta que España, pese al avance de las últimas tres décadas todavía se encuentra muy retrasada en la consolidación del estado del bienestar tal como lo demuestran los datos de Eurostat que señalan que globalmente el gasto público de nuestro país supuso en 2006 un 38,5 por ciento del PIB, mientras que la media de la Unión Europea, sea a 15 miembros a los que se refiere el gráfico siguiente, donde España ocupaba el penúltimo lugar solo por delante de Irlanda, o al total de los 27 , se situaba en torno al 46 por ciento.

UE-15 Gasto público en porcentaje del PIB 2006

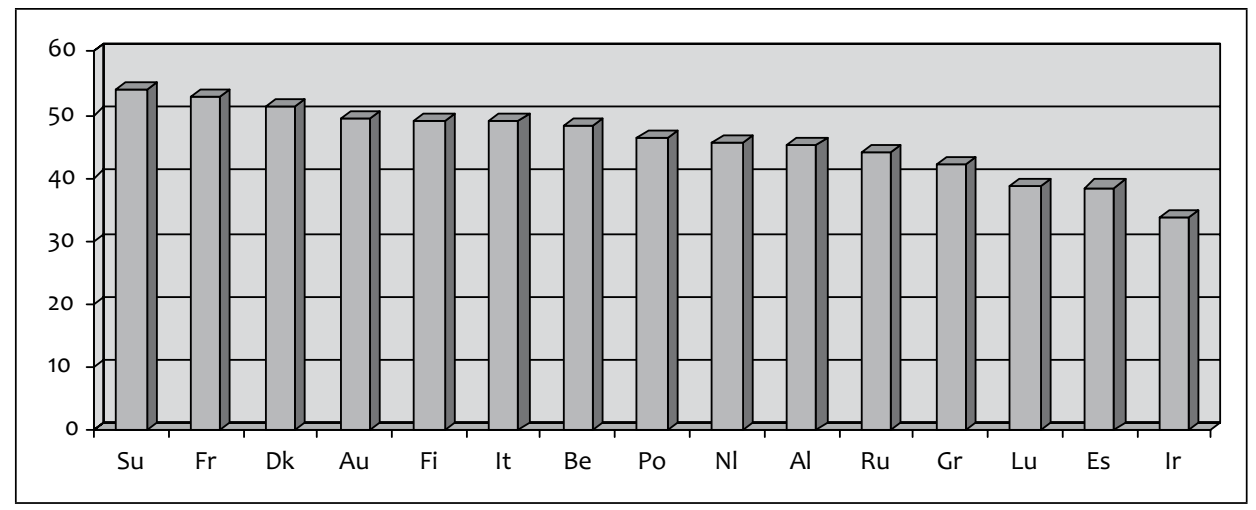

Fuente: Eurostat y Banco Central Europeo. 
En el caso de España hay que señalar de ese nivel de gasto solamente un 36 por ciento corresponde al, presupuesto de la Administración General del Estado mientras que a las Comunidades Autónomas y Corporaciones locales les corresponden respectivamente porcentajes del 22 por ciento y 13 por ciento, en tanto que el 29 por ciento restante corresponde al presupuesto de la Seguridad Social ${ }^{4}$.

Por último, y por aportar los datos más recientes, sobre este aspecto del asunto la Presentación del Proyecto de Presupuestos Generales del Estado para 2011 elaborada por el Ministerio de Economía y Hacienda señala lo siguiente:

"Atendiendo al nivel de gastos no financieros, el peso de las administraciones públicas sobre el Producto Interior Bruto (PIB), alcanza en España en 2009 el 49 por ciento del PIB, un nivel tanto inferior a la media de la Zona Euro, un 50,8 por ciento del PIB, como al de la Unión Europea (UE), un 50,7 por ciento. De hecho, España se sitúa entre los diez países de la UE con menor gasto público en porcentaje del PIB, a bastante distancia de los niveles de las grandes economías de la Zona Euro, como Francia, Italia, Reino Unido y Alemania." ${ }^{5}$

\section{Consideración sobre la evolución de efectivos en la Administración General del Estado}

Retomando el hilo de nuestro tema principal, señalemos que, como hemos visto, el personal adscrito a los Ministerios, OO.AA. y Áreas vinculadas a los mismos, esto es, lo que se ha dado en llamar Administración General del Estado ascendía en julio de 2009 a un total de 233.995 efectivos. Esta cifra, de acuerdo con los resultados del proceso de aplicación del modelo territorial consagrado en la Constitución Española, ha continuado reduciéndose en la última década, cuando ya las transferencias de competencias a las Comunidades Autónomas han tenido un carácter testimonial por su reducido volumen. Por ello, el número de personas existentes en julio de 2000 en la Administración General del Estado en el ámbito de carácter más burocrático (excluidas las Fuerzas Armadas, las Fuerzas y Cuerpos de la Seguridad del Estado, la Administración de Justicia y las Entidades Públicas Empresariales), todavía se contrajo en un 9,9\% hasta llegar a la cifra de 238.251 personas de julio de 2009 que proporciona el Boletín Estadístico del Personal al Servicio de las Administraciones Públicas.

4 "Presentación del Proyecto de Presupuestos Generales del Estado para 2007".

5 "Presentación del Proyecto de Presupuestos Generales del Estado para 2011"(libro amarillo), pág. 16. MEH, octubre 2010. 
Evolución del número de efectivos de la Administración General del Estado

(2000-2009)

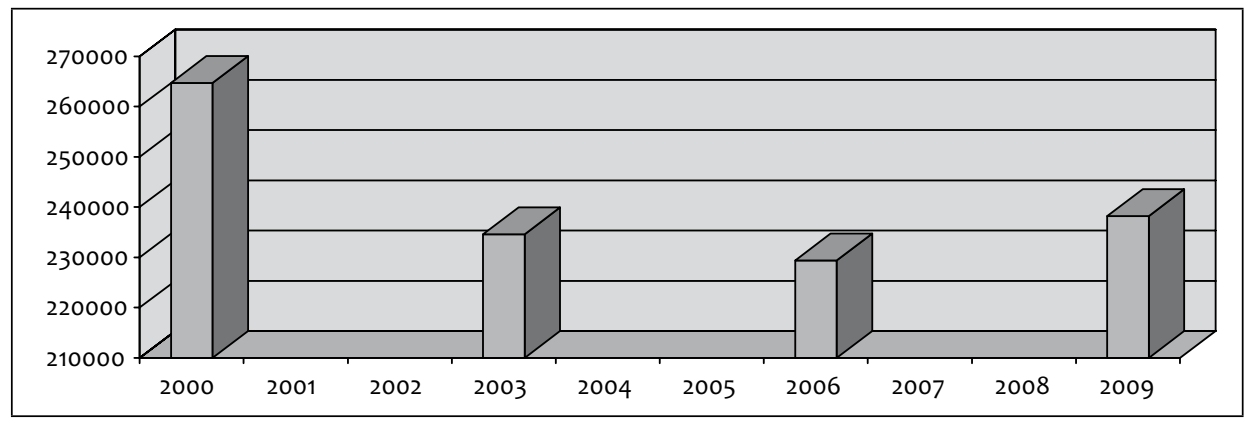

Fuente: Boletín Estadístico del Personal al Servicio de las Administraciones Públicas. Por razones de homogeneidad el Boletín no computa en esta evolución al personal que presta sus servicios en la Instituciones sanitarias de la Seguridad Social (1.614 personas).

Como se observa, se ha producido una clara disminución del número de efectivos que, una vez que ya se había llevado a cabo el grueso del proceso de transferencia de competencias y efectivos del Estado a las Comunidades Autónomas, básicamente obedece a que las Ofertas de Empleo Público de la Administración General del Estado del periodo 1997-2002 tuvieron un carácter notablemente restrictivo al haberse establecido una tasa de reposición del 25 por ciento respecto de las bajas producidas en el ejercicio anterior. En 2002 está estrategia de contención desapareció y se permitió la reposición de la totalidad de las bajas producidas. Ello explica el incremento de los efectivos de la Administración General del Estado en los últimos tres años (la larga duración de los procesos de selección implica un retraso de dos años para que exista repercusión en la cuantía de los efectivos) que se manifiesta claramente en el gráfico en el repunte correspondiente a 2009.

Sin embargo, la orientación adoptada por el Gobierno de la Nación en relación con la Oferta de Empleo Público para 2009 que de nuevo limitó a un 30 por ciento la tasa de reposición de las bajas producidas y especialmente las características absolutamente restrictivas que la Oferta de Empleo de la Administración General del Estado para 2010 ha tenido, fijando una tasa global de reposición de las bajas de únicamente el 10 por ciento, como consecuencia de la necesidad de reducir el déficit público en el marco de las acciones frente a la crisis económica global, de nuevo acentuará la tendencia de reducción de efectivos en la AGE.

Las medidas adicionales adoptadas por el Gobierno para alcanzar los objetivos de estabilidad presupuestaria en los próximos años básicamente mediante el Real Decreto-Ley 8/2010, de 20 de mayo, por el que se adoptan medidas extraordinarias para la reducción del déficit público, y aquellas que se derivarán del Acuerdo Marco alcanzado por el Consejo de Política Fiscal y Financiera en junio de 2010 para acelerar la reducción del déficit público, sin duda van a suponer una acentuación de las medi32 importante del número de efectivos de la Administración General del Estado. 
En cualquier caso, sin que en estos momentos cuestionemos de ningún modo la necesidad de adoptar estas medidas, será necesario ineludiblemente a un plazo de tres-cinco años evaluar los efectos de esta política de efectivos restrictiva sobre la consecución de los objetivos de las distintas políticas públicas en curso.

En este sentido el documento de Presentación del Proyecto de Presupuestos Generales del Estado para 2011 señala que "el objetivo de la actual reducción del gasto público no es alcanzar un determinado tamaño que pudiera considerarse óptimo, sino adecuar los niveles de gasto a los niveles reales de ingresos. Adicionalmente esta es una oportunidad para incrementar la eficiencia de dicho gasto público, realizando una re-

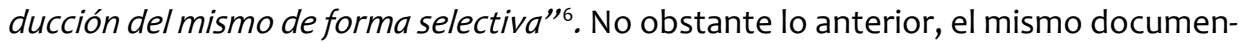
to al referirse al empleo público menciona la menor cuantía proporcional del mismo en relación con los demás países desarrollados: "En este sentido, recurrir a los estudios de la OCDE en este ámbito resulta los más prudente y fiable para obtener datos comparables, si bien los últimos publicados se refieren al año 2005. De acuerdo con los mismos, el empleo público en España, un 13,7 por ciento de la población activa, se encuentra en niveles inferiores al de la mayoría de los países analizados, y a bastante distancia de países como Francia, un 25,2 por ciento, o Suecia, un 28,8 por ciento, entre otros."7

\section{Consideración sobre la titulación académica y el nivel profesional de los efectivos de la AGE}

Hasta este momento nos hemos centrado en describir cuál es la dimensión del ámbito sobre el que versa este trabajo, hemos visto ya cuál es el volumen de los efectivos de la Administración Pública Estatal y lo hemos puesto en relación con el resto de las Administraciones Públicas, habiéndose manifestado que la Administración Pública Estatal es ya en estos momentos la más reducida de las tres Administraciones Públicas como consecuencia de la aplicación del modelo de descentralización política y administrativa establecido en la Constitución de 1978. Hemos visto también como la evolución de los efectivos de la Administración General del Estado, el núcleo esencialmente burocrático, ya no prestador de servicios, ha seguido disminuyendo como tendencia general en la última década y va a proseguir en esa tendencia de reducción, lo que parece coherente con el proceso de transferencia de competencias de gestión y prestación de servicios a las Comunidades Autónomas con carácter general y con las acciones coyunturales de lucha contra el déficit público.

Conviene ahora que, como tercer paso, nos detengamos a analizar la estructura profesional interna de los efectivos de la AGE, utilizando siempre como base los da-

6 “Presentación del Proyecto de Presupuestos Generales del Estado para 2011" (libro amarillo), pág. 16. MEH, octubre 2010.

7 “Presentación del Proyecto de Presupuestos Generales del Estado para 2011" (libro amarillo), pág. 17. MEH, octubre 2010. 
tos proporcionados por el Boletín Estadístico del Personal al Servicio de las Administraciones Públicas.

La Ley 30/1984, de Medidas para la Reforma de la Función Pública, clasificó los Cuerpos y Escalas que formaban la función pública en cinco grupos ( $A, B, C, D$ y E) concordantes con los diferentes niveles de titulación académica, de tal modo que para acceder a un Cuerpo del Grupo A era preciso estar en posesión de un título de Doctor, Licenciado, Ingeniero, Arquitecto o equivalente y para acceder a uno del Grupo E era preciso el Certificado de Escolaridad. Más recientemente, la Ley 7/2007, 12 de abril, del Estatuto Básico del Empleado Público, ha modificado esta clasificación para aproximarla a la existente en las instituciones de la Unión Europea, y al "modelo de Bolonia", del siguiente modo:

\begin{tabular}{|l|l|l|}
\hline \multicolumn{1}{|c|}{ Grupo } & \multicolumn{1}{|c|}{ Subgrupo $\left(^{*}\right)$} & \multicolumn{1}{c|}{ Titulación requerida } \\
\hline A & $\begin{array}{l}\mathrm{A} 1[\mathrm{~A}] \\
\mathrm{A} 2[\mathrm{~B}]\end{array}$ & Título universitario de Grado \\
\hline B & & Técnico Superior \\
\hline C & $\begin{array}{l}\mathrm{C} 1[\mathrm{C}] \\
\mathrm{C} 2[\mathrm{D}]\end{array}$ & $\begin{array}{l}\text { Bachiller o Técnico Graduado en educación } \\
\text { secundaria obligatoria }\end{array}$ \\
\hline $\begin{array}{l}\text { Otras agrupaciones } \\
\text { profesionales }\end{array}$ & $\mathrm{E}$ & $\begin{array}{l}\text { Sin necesidad de titulaciones de sistema } \\
\text { educativo }\end{array}$ \\
\hline
\end{tabular}

${ }^{*}$ ) Entre corchetes figura la correspondencia con los grupos de la Ley 30/1984.

De acuerdo con esta nueva clasificación establecida en el EBEP, la distribución de los efectivos de la Administración General del Estado entre los distintos Subgrupos es la siguiente ${ }^{8}$ :

Distribución de los funcionarios de la AGE por Subgrupos

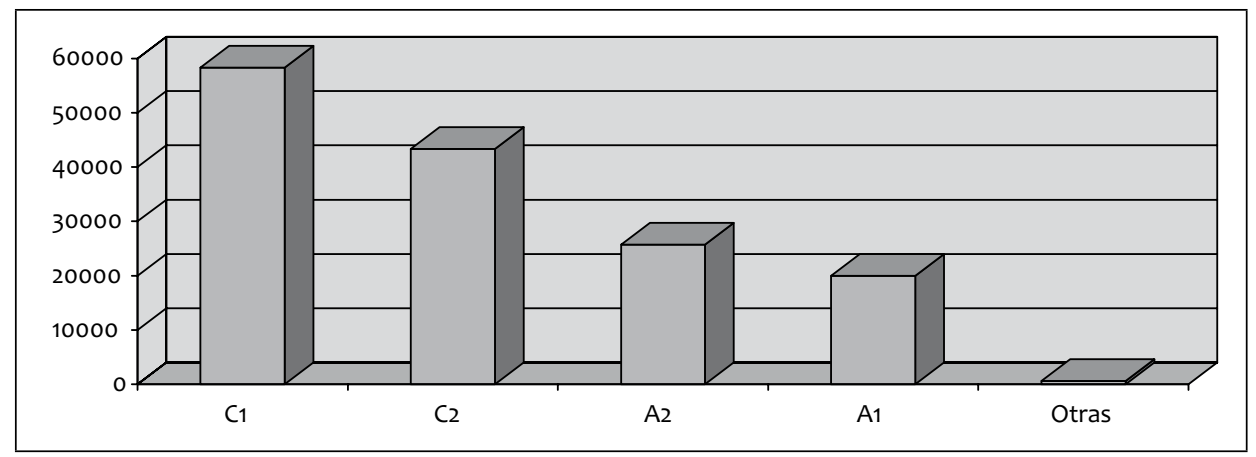

Fuente: Boletín Estadístico del Personal al Servicio de las Administraciones Públicas (Junio 2009).

8 Fuente: Boletín Estadístico del Personal al Servicio de las Administraciones Públicas (Junio 2009). No incluye Fuerzas y Cuerpos de la Seguridad del Estado, Fuerzas Armadas, Administración de Justicia, 34 Entidades Públicas Empresariales, Docencia no universitaria ni Instituciones Sanitarias de la Seguridad
Social. 
Si atendemos a la correspondencia de estos subgrupos del EBEP con la exigencias de titulación de la Ley de Medidas para la Reforma de la Función Pública, esta distribución muestra que para la realización de tareas burocráticas (dirección, planificación, coordinación, evaluación ... ) en los ministerios, organismos dependientes y áreas vinculadas a los mismos la Administración General del Estado cuenta con 20.000 funcionarios de carrera, titulados superiores universitarios de los anteriores a la ordenación académica del Espacio Europeo de Educación Superior, de un total de 150.000 en tanto que dispone de 103.000 profesionales con titulación de enseñanza secundaria.

Concordante con lo anterior, la distribución por niveles profesionales es la siguiente:

\begin{tabular}{|c|c|}
\hline Nivel & Número de funcionarios \\
\hline 30 & $2.312\left({ }^{*}\right)$ \\
\hline 29 & 1.963 \\
\hline 28 & 6.398 \\
\hline $27-26$ & 14.496 \\
\hline $25-24$ & 12.764 \\
\hline $23-18$ & 49.043 \\
\hline $17-10$ & 62.173 \\
\hline Total & 149.494 \\
\hline
\end{tabular}

(*) Incluye Embajadores.

Ello significa que del total de los funcionarios de la Administración General del Estado, solamente un 2,8 por ciento desempeñan puestos del máximo nivel de capacitación y responsabilidad profesional (niveles 29 y 30 del puesto de trabajo) con el apoyo inmediato de otro 4,2 por ciento que corresponde a los 6.398 funcionarios Coordinadores o Jefes de área de nivel 28.

Distribución de los funcionarios de la AGE por niveles

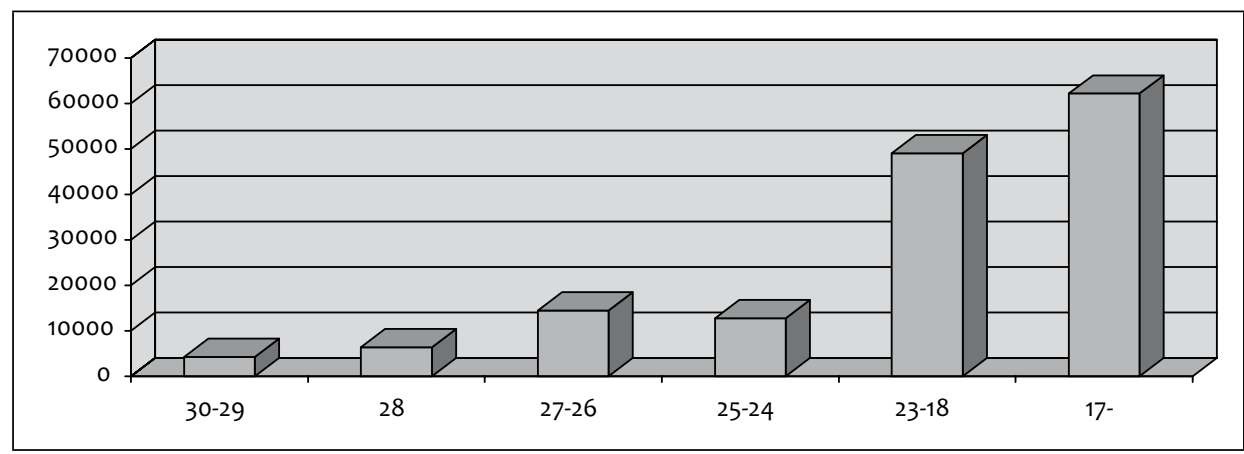

Fuente: Boletín Estadístico del Personal al Servicio de las Administraciones Públicas (Junio 2009). 
Por el contrario la mayor concentración de efectivos, 111.216 funcionarios que suponen el 74,4 por ciento del total se produce entre los niveles 23 y 10 de carácter administrativo y auxiliar, lo que parece absolutamente desproporcionado para una administración escasamente prestadora de servicios, si se exceptúan la función policial y la administración de la Seguridad Social, en la que ineludiblemente deben tener una importancia primordial (deben constituir el core, como se dice en términos de empresa) las funciones de dirección, planificación, elaboración de políticas, definición de programas y proyectos, control de resultados, evaluación, control económico y presupuestario, etc. que se encuentran manifiestamente infradotadas en nuestra Administración General del Estado según se desprende de los datos expuestos.

A iguales conclusiones se llega por la vía de comparar la evolución de los efectivos de los distintos grupos en el período 1990-2008. Los autores de un trabajo ${ }^{9}$ que incluye este aspecto señalan lo siguiente:

“(...) la estructura de la AGE no ha cambiado demasiado en los últimos 18 años, a pesar de que la misma ha perdido buena parte de sus competencias de gestión. No parece que la AGE haya modificado su estructura de personal hacia una Administración más cualificada y pensante. (...) vemos que el grupo A1 es el que menos ha evolucionado en este tiempo, no solo en cuanto al número de efectivos, que ha disminuido, sino en cuanto al peso específico respecto al total que pasa del $11 \%$ al $13 \%$. (...) El grupo C1 es uno de los más curiosos en cuanto a su evolución, ya que en el año 2008 es, con diferencia, el más numeroso de todos, llegando a suponer hasta un 39\% del total de ese año, es decir, más que la suma del grupo A1 y A2 juntos."

\section{LA PERCEPCIÓN DE LOS CIUDADANOS SOBRE LA ADMINISTRACIÓN GENERAL DEL ESTADO}

No disponemos de estudios específicos acerca de la percepción que los ciudadanos tienen de la Administración General del Estado por lo que debemos recurrir a resultados extraídos de estudios de opinión más amplios que incluyen esta materia, esencialmente los Latinobarómetros, los Barómetros y los Estudios de Calidad sobre los servicios públicos que periódicamente lleva a cabo el Centro de Investigaciones Sociológicas dependiente del Ministerio de Presidencia. No obstante, será inevitable que en algún caso, por su interés, proporcionemos datos que se refieran al conjunto de las Administraciones Públicas y no solo a la Administración General del Estado.

\section{Grado de satisfacción con las Administraciones Públicas}

Preguntados los encuestados en general sobre su grado de satisfacción con el conjunto de las Administraciones Públicas en España los resultados oscilan entre la

9 Juan A. Garde y Lorena González. "Evolución de la estructura y del gasto en la AGE”, publicado en “La Reforma de la Administración General del Estado”, edit. PriceWaterhouse, Madrid 2010, págs. 137 y 138. 
impresión negativa y la positiva según sea el momento de la encuesta y la finalidad de la misma. Así, cuando se les pregunta en el marco de una encuesta de carácter general un 38,6 por ciento tiene una percepción negativa (bastante negativa 31,9 por ciento y muy negativa 6,7 por ciento) mientras que un 28,7 por ciento la tiene positiva $(1,3$ por ciento muy positiva y el 27,4 por ciento bastante positiva $)^{10}$. La Lentitud en la tramitación y la Burocracia y el papeleo ocupan los primeros lugares entre las características atribuidas en general a la Administración, ya que un 43,1 por ciento de los encuestados sitúa la Lentitud como primer problema y un 19,6 por ciento como segundo, en tanto que un 32,1 por ciento sitúa en primer lugar la Excesiva burocracia y el papeleo y un 31,8 por ciento lo hace en segundo lugar"1.

Un año antes con ocasión de un estudio específico sobre la calidad en lo servicios públicos, las respuestas habían sido mejores para las Administraciones: un 35,9 por ciento declaraba tener una percepción muy positiva (2,6 por ciento) o bastante positiva (33,4 por ciento). Está impresión general mejora notablemente cuando la pregunta se refiere concretamente al resultado de las gestiones realizadas en el último año en algún centro de la Administración, en ese caso el 59,4 por ciento muestra un alto grado de satisfacción con el resultado (10,9 por ciento muy satisfecho y 48,6 por ciento bastante satisfecho) frente al 20,1 por ciento que se muestran poco satisfechos y al 12,3 por ciento que quedaron nada satisfechos ${ }^{12}$.

\section{Nivel de satisfacción con las gestiones realizadas en el último año en algún centro de la Administración Pública}

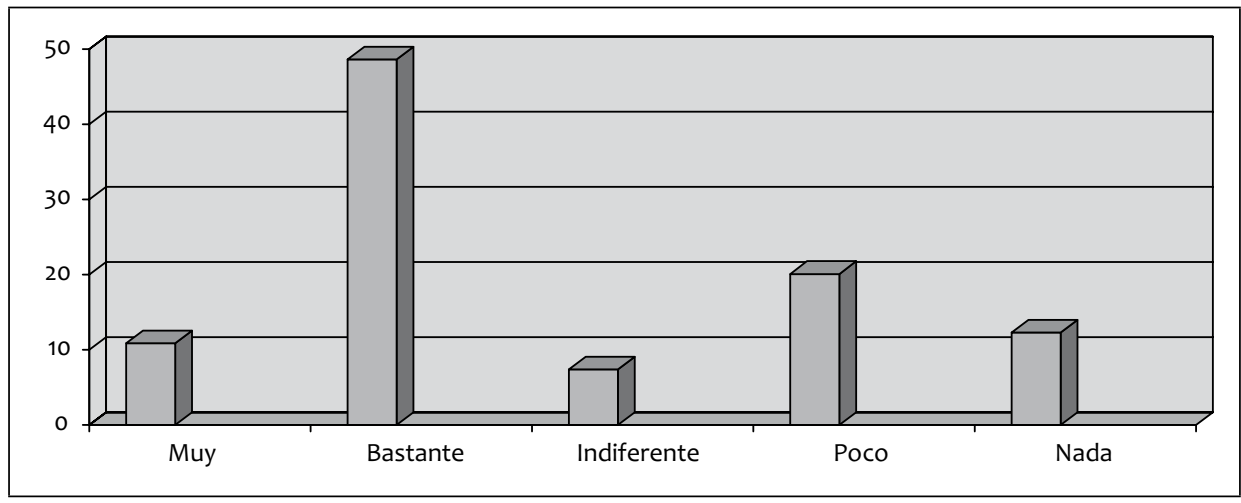

Como vemos, la impresión inicialmente negativa, considerada aquella en abstracto, mejora cuando se pregunta por el grado de satisfacción con el resultado de las gestiones realizadas durante el último año. Cuando se pregunta si el servicio recibido ha sido mejor, igual o peor de lo que se esperaba a priori, el 40 por ciento responde que el servicio recibido ha sido mejor de lo que esperaba, en tanto que el 23 por ciento respon-

\footnotetext{
10 CIS, Barómetro. Marzo 2009.

11 CIS, Barómetro. Marzo 2009.

12 CIS, Calidad de los servicios públicos. Mayo 2008.
} 
de que peor ${ }^{13}$. Esta percepción positiva una vez producido el encuentro con las Administraciones Públicas es coincidente con la que desde hace décadas viene observándose en el caso de los estudios específicos que se realizan en la sanidad pública, donde con niveles valorativos generales medios o negativos a priori, se producen valoraciones positivas que superan el 80 por ciento tras las hospitalizaciones, intervenciones quirúrgicas, etc. En cualquier caso sigue resultando preocupante tanto el bajo nivel de satisfacción como que un altísimo 72,2 por ciento manifieste haber encontrado dificultades en la realización de sus gestiones ${ }^{14}$ sin que sirva de consuelo el hecho de que el 43,3 por ciento considere que en los últimos diez años se ha mejorado el funcionamiento de la Administración frente a un 18,1 por ciento que considera que ha empeorado ${ }^{15}$.

\section{Grado de satisfacción con la AGE}

La Administración General del Estado es percibida como la Administración más importante, si se nos permite la expresión, de las existentes en cuanto a responsabilidad. Pese al intenso proceso de transferencia de competencias a las Comunidades Autónomas al que nos hemos referido, el 38,1\% de los encuestados señala ${ }^{16}$ que la Administración del Estado es la principal responsable de la prestación de los servicios públicos, seguida a notable distancia por las Comunidades Autónomas (17,5 por ciento) y por los Ayuntamientos (15,1 por ciento).

¿Quién es el principal responsable de la prestación de los servicios públicos?

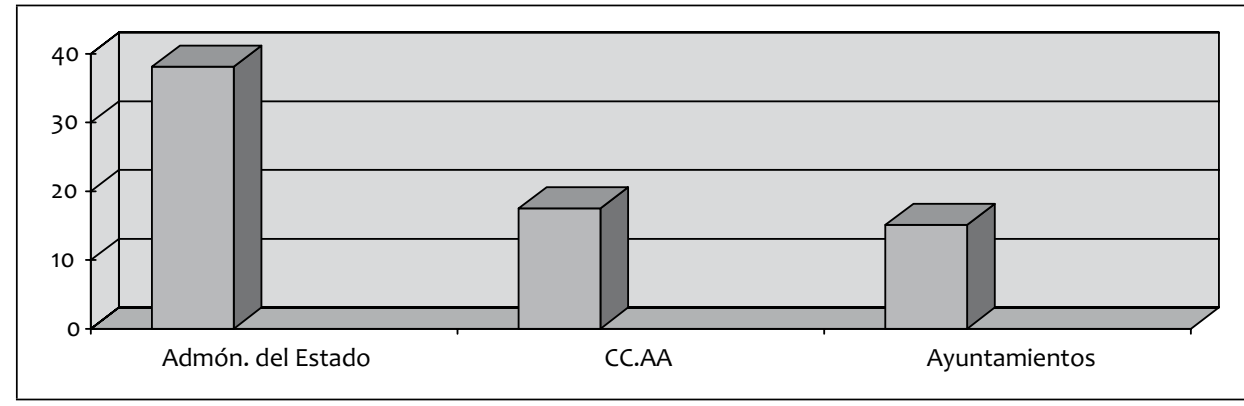

Asimismo se considera que la Administración del Estado tiene el personal más preparado, 25,1 por ciento de los encuestados, frente a las Comunidades Autónomas, 15,9 por ciento o los Ayuntamientos con un 11,2 por ciento ${ }^{17}$.

En lo que concierne al grado de satisfacción, se dan niveles superiores a los que vimos anteriormente entre los que han realizado algún trámite a lo largo del último

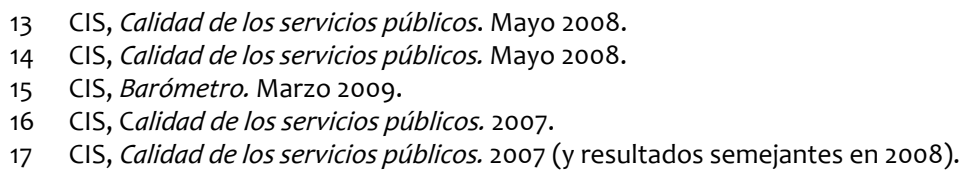


año, el 64 por ciento responde que está muy satisfecho (13,5 por ciento) o bastante satisfecho (50,4 por ciento) $)^{18}$.

Nivel de satisfacción tras trámites realizados personalmente en algún centro de la AGE

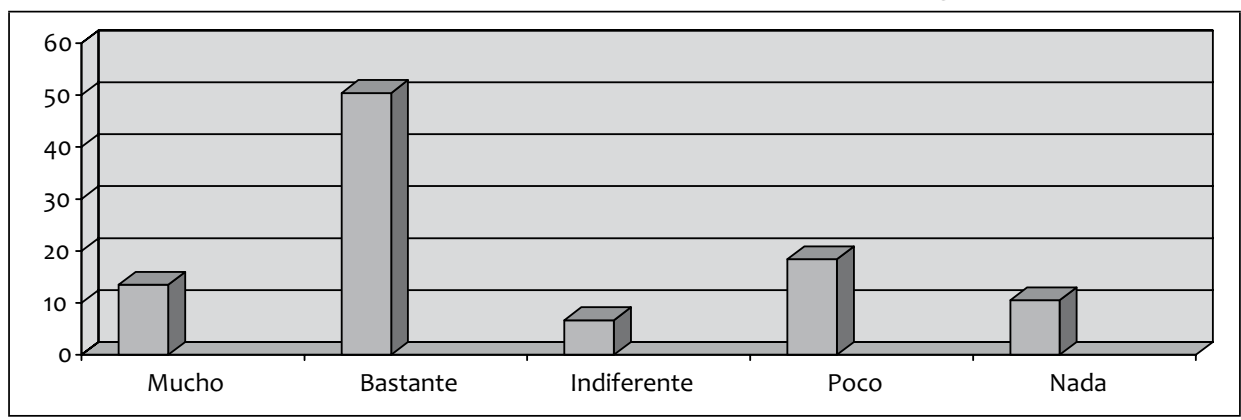

Pero esta satisfacción relativamente alta que probablemente tiene relación con que una parte importante de las gestiones (34 por ciento en Hacienda y 18 por ciento en la Seguridad Social ${ }^{19}$ ) se han realizado en áreas en las que en los últimas décadas se han efectuado fuertes inversiones en la mejora de los servicios a través de las Tecnologías de la Información y las Comunicaciones, ya que un 75 por ciento de los encuestados $^{20}$ manifiesta que en los últimos años se ha producido una mejora en la Administración General del Estado en lo concerniente a la utilización de las Nuevas Tecnologías. Sin embargo esta valoración positiva en este aspecto concreto no enmascara el hecho de que son mayoría los que señalan tener poca (34,7 por ciento) o ninguna (16,4 por ciento) confianza en la Administración General del Estado, frente a los que dicen confiar algo (39,9 por ciento) o mucho (5,8 por ciento) $)^{21}$.

Nivel de confianza en la Administración del Estado

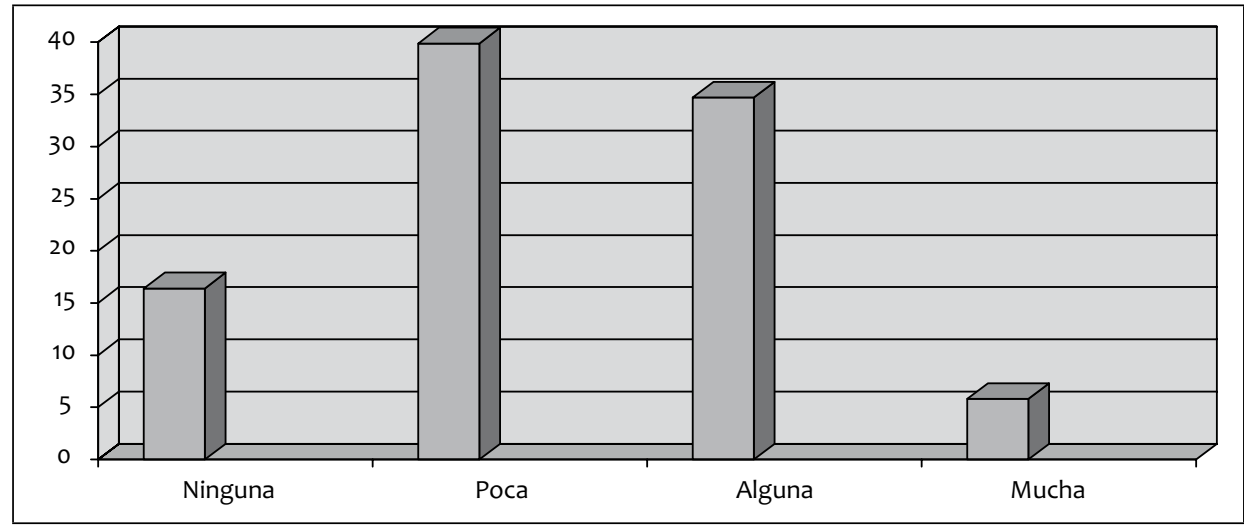

18 CIS, Calidad de los servicios públicos. 2007.

19 CIS, Calidad de los servicios públicos. 2007.

20 CIS, Calidad de los servicios públicos. 2007.

21 CIS, Latinobarómetro. Nov-Dic. 2009. 
Tampoco es positiva la puntuación alcanzada en una escala de 1 a 10 para valorar a la Administración del Estado a partir de adjetivos de signo opuesto atribuibles a ella, en donde la media obtenida está por debajo de 5 y se la considera Lenta, No participativa, Opaca y Rígida, y superando luego muy levemente el 5 siendo calificada en mejor medida como Eficaz, Preocupada por mejorar el servicio y Otorgadora de confianza ${ }^{22}$.

\section{La utilización de Internet}

Nos hemos referido anteriormente al positivo reconocimiento de los ciudadanos en cuando a la mejora lograda por la Administración en materia de utilización de las Tecnologías de la Información y las Comunicaciones. Esta incorporación tecnológica, que a partir de los años 80 permitió introducir mejoras procedimentales que redundaban esencialmente en la reducción de los tiempos de tramitación, ${ }^{23}$ ha dado paso en nuestros días a la aparición de la Administración Electrónica cuyo exponente más visible todavía es la realización de trámites administrativos por Internet, sea en su modalidad más avanzada -la Oficina sin papeles, caso de la Agencia Estatal de Administración Tributaria- o en otras previas a ello y más modestas como la obtención de información, la descarga de formularios, el establecimiento de citas, etc.

En esta materia es de destacar que el 71,8 por ciento de los encuestados ${ }^{24}$ manifiestan haber oído hablar de la posibilidad de realizar gestiones por Internet frente a un 27,9 por ciento que responde negativamente. Ya en 2007 el 74 por ciento manifestaba haber oído hablar de la mejora que para el funcionamiento de la Administración supondría la implantación del DNI electrónico ${ }^{25}$.

Sin embargo, siendo aceptable el grado de información que los ciudadanos tienen acerca de la posibilidad de relacionarse electrónicamente con la Administración desde su casa o desde el trabajo, todavía sigue siendo muy reducido el número de aquellos que se muestran dispuestos a hacerlo. Preguntados acerca de sus preferencias acerca de la forma de realizar gestiones con la Administración, el 71,9 por ciento situó en primer lugar la gestión personal y un 16,1 por ciento optó por dicha forma en segundo lugar; el teléfono fue situado en primer lugar por el 6,7 por ciento y en segundo lugar por el 50 por ciento, mientras que Internet se situó en primer lugar en el 19,7 por ciento de las respuestas y en segundo en el 17,9 por ciento. Es decir, existe todavía entre los ciudadanos una importante resistencia o reticencia hacía el uso de Internet para relacionarse con la Administración, lo que no resulta extraño si atendemos a las exiguas cifras del comercio electrónico que existen en España ya que éste

22 CIS, Calidad de los servicios públicos. 2007

23 En la Seguridad Social, por ejemplo, la informatización de la documentación permitió pasar en 1989 de una media superior a los cuatro meses para el reconocimiento de las pensiones a poco más de veinte días.

$40 \quad 24 \quad \begin{array}{ll}\text { CIS, Barómetro. Marzo } 2009 . \\ 25 & \text { CIS, Calidad de los servicios públicos. } 2007\end{array}$ 
representaba a finales de 2008 solamente el 8,3 por ciento del total de las ventas realizadas, muy inferior al volumen de otros países de la Unión Europea a 15 o a $27^{26}$.

Preferencias para relacionarse con la Administración

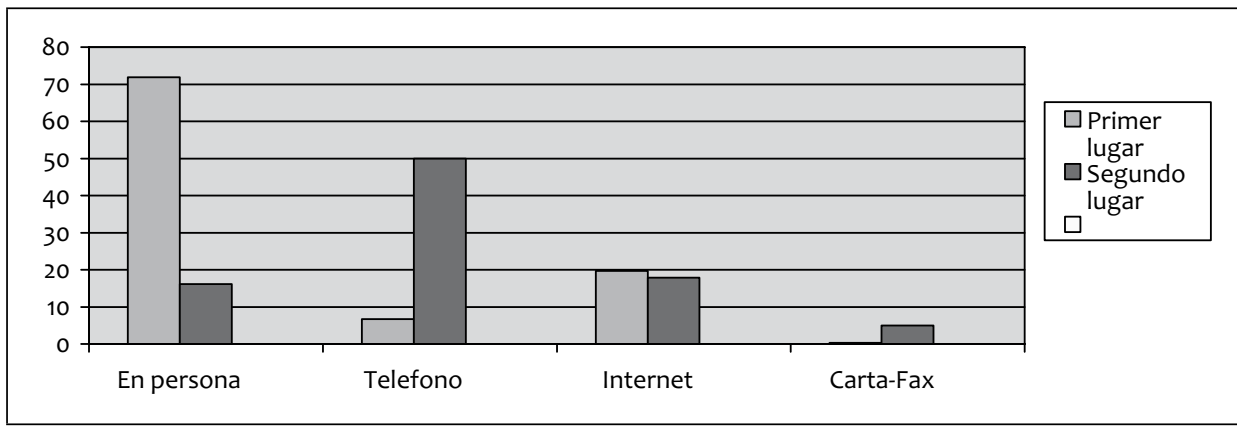

Esta resistencia de las personas a utilizar Internet es coincidente con la baja utilización que de la red hacen las empresas cuando ésta posibilidad es voluntaria. Así por ejemplo, en 2005 el Instituto Nacional de Estadística puso en funcionamiento el sistema ARCE (Almacenamiento y Recogida de Cuestionarios Económicos) que permite a las empresas cumplimentar por Internet las encuestas económicas del INE. Dado que la remisión al INE por esta vía no superaba el 20 por ciento del total, a finales de 2007 el organismo llevó a cabo una encuesta para conocer las causas de tan baja utilización de un mecanismo que resultaba más rápido y cómodo para las empresas. Los resultados mostraron que el 50 por ciento "prefería otros medios", el 25 por ciento "no conocía el servicio", el 11 por ciento alegó "problemas técnicos", un 7 por ciento "no tener Internet" y un 3 por ciento "no creerlo seguro"27.

Los resultados de los estudios realizados muestran que del 26,5 por ciento de ciudadanos que contactan con la Administración a través de Internet, el 61 por ciento lo hace con la Administración General del Estado, el 24\% con las Comunidades Autónomas y el 12 por ciento con los Ayuntamientos, siendo Hacienda el área que tiene una mayor demanda (45,6 por ciento).

En la Administración General del Estado, de los ciudadanos que realizaron sus trámites por Internet un $71,9 \%$ obtuvo un alto grado de satisfacción y para un $9,7 \%$ resultó una experiencia negativa ${ }^{28}$. Es destacar el incremento de la satisfacción cuan-

26 Fuente: Comisión del Mercado de las Telecomunicaciones. Tomado de Elena Cidón (RED.ES), Secretaría de Estado de Telecomunicaciones y para la Sociedad de la Información del Ministerio de Industria, Comercio y Turismo

27 Gálvez, Maldonado y Ballano, “Administración electrónica, el intercambio de información entre administraciones y la reducción de carga administrativa a los ciudadanos y empresas: La experiencia del INE" en "La Administración Electrónica y el servicio a los ciudadanos". Ministerio de Economía y Hacienda, Madrid 2009.

28 CIS, Calidad de los servicios públicos. 2007 
do las gestiones se realizan por Internet, comparada con la obtenida con carácter general que era del $64 \%$ tras realizar trámites personalmente, como vimos anteriormente.

Nivel de satisfacción tras realizar trámites con la AGE por Internet

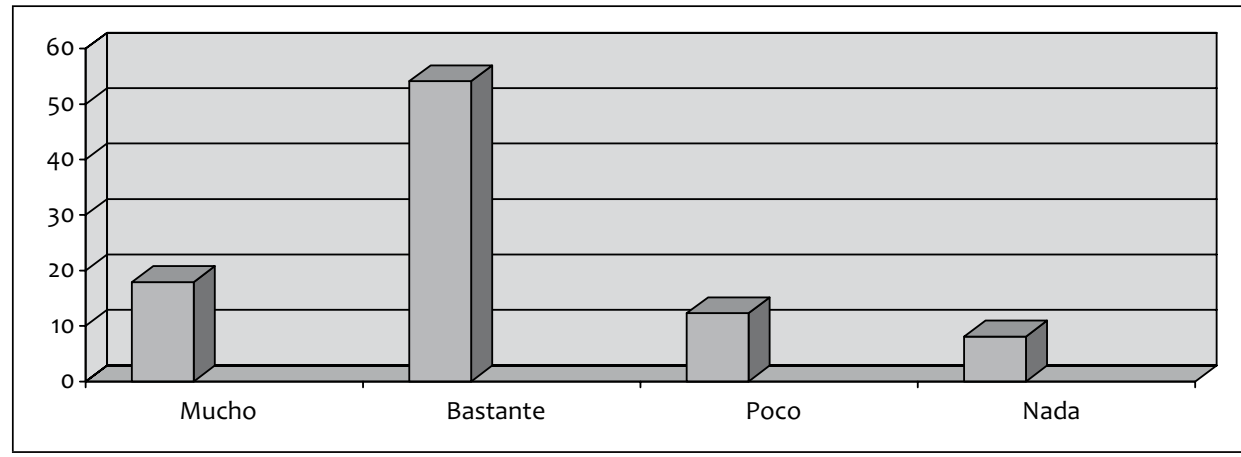

En cuanto al objetivo de la gestión integral a través de Internet, como ya hemos señalado todavía no se explota adecuadamente el potencial de las Tecnologías de la Información y las Comunicaciones; el 30 por ciento de los entrevistados manifiesta que utilizaron la red para obtener información, el 24,4\% para descargar formularios y solo un 29,1 por ciento para realizar trámites on line ${ }^{29}$.

Los Planes de la Administración General del Estado "Avanza" y "Moderniza", la implantación y fomento del uso del DNI electrónico y la Ley 11/2007 de acceso electrónico de los ciudadanos a los servicios públicos marcan el camino a seguir en esta materia con el fin de mejorar la productividad tanto de la Administración como de las empresas y de reducir las cargas burocráticas en la actividad económica y de los ciudadanos en su relación con aquella, ya que no debemos olvidar que la Administración Electrónica no se acaba en que los ciudadanos puedan realizar los tramites con la Administración a través de Internet sino que debe constituir un elemento más que contribuya al desarrollo económico y social de los países, en nuestro caso España.

\section{Comparación con la empresa privada}

Por último, la opinión de los ciudadanos cuando se les solicita que comparen el funcionamiento de la empresa privada y el de la Administración Pública está claramente decantada a favor de la primera. Una pregunta planteada en términos de asociar determinados valores al sector público y al sector privado resulta abrumadoramente favorable a este último; solamente en lo que se refiere a la Preocupación por 
la igualdad y a la Posibilidad de participación de los usuarios la opinión es favorable al sector público ${ }^{30}$.

\begin{tabular}{|l|c|c|}
\hline & Sector público & Sector privado \\
\hline Eficacia & 19,6 & 51,4 \\
\hline Responsabilidad en el trabajo & 18,9 & 47,9 \\
\hline Calidad en el servicio & 21,3 & 50,1 \\
\hline Profesionalidad & 22,5 & 37,8 \\
\hline Preocupación por la igualdad & 46,8 & 17,3 \\
\hline Preocupación por la satisfacción del usuario & 22,4 & 45,6 \\
\hline Burocracia & 57,9 & 14,6 \\
\hline Innovación & 21,5 & 44,7 \\
\hline Motivación en el trabajo & 15,0 & 50,3 \\
\hline Buena organización & 16,3 & 46,9 \\
\hline Posibilidad de participación de los usuarios & 35,2 & 21,3 \\
\hline Salarios acordes con los resultados del trabajo & 24,5 & 37,1 \\
\hline
\end{tabular}

Sin embargo, pese a esta abrumadora opinión favorable al sector privado o desfavorable para lo público, paradójicamente los ciudadanos no consideran que la privatización de los servicios o su externalización sean la solución para remediar los aspectos negativos del funcionamiento de la Administración Pública; hay prácticamente el mismo número de los que opinan que los servicios públicos funcionan mejor cuando están gestionados por organizaciones o empresas privadas (29,2\%) que el de los que opinan que funcionan peor en ese caso (27 por ciento) ${ }^{31}$.

Opinión sobre el funcionamiento de los servicios públicos gestionados por empresas privadas

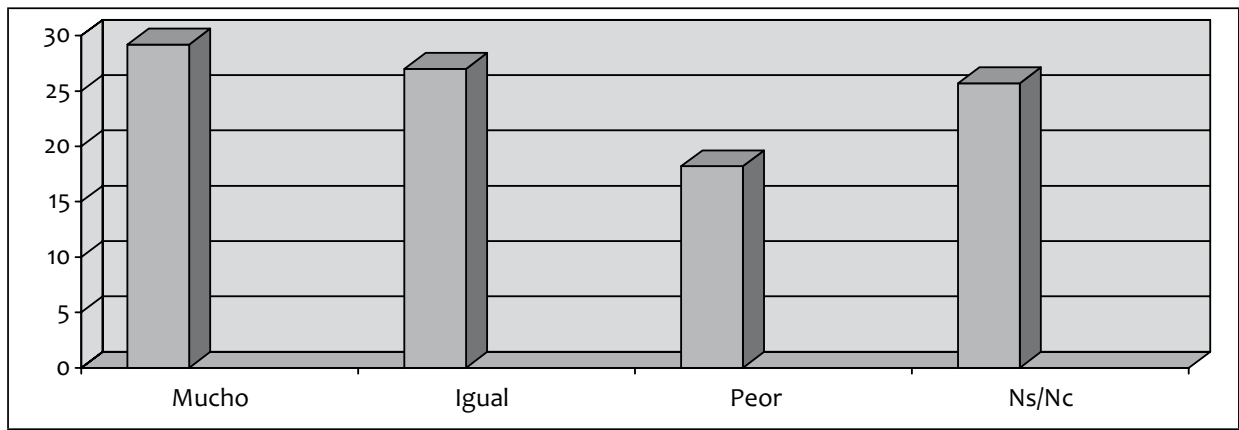

30 CIS, Calidad de los servicios públicos. 2007

31 CIS, Calidad de los servicios públicos. Mayo 2008 


\section{LOS PROCESOS DE REFORMA Y MODERNIZACIÓN DE LA ADMINISTRACIÓN GENERAL DEL ESTADO}

Una vez que hemos visto la dimensión del ámbito sobre el que versa este trabajo y la percepción que los ciudadanos tienen de la Administración General del Estado, nos referiremos ahora a los procesos de cambio que han tenido lugar en nuestra Administración en las últimas décadas.

A partir del proceso de transición política a la democracia y una vez reestablecida ésta tras el paréntesis de la Dictadura franquista, la necesidad de llevar a cabo una profunda transformación de la Administración heredada del régimen anterior, siquiera fuera para adecuarla a los principios constitucionales y para desarrollar los derechos y libertades establecidos en la Constitución, era evidente y urgente. Sin embargo, como también resulta comprensible, los primeros gobiernos de la democracia, ocupados en problemas de mayor envergadura política no lograron llevar a cabo ninguna reforma pese a los intentos de que se aprobara mediante ley una nueva regulación de las bases del régimen estatutario de funcionarios que fuese aplicable al conjunto de las Administraciones Públicas y resolviese los problemas más acuciantes ${ }^{32}$.

\section{La reforma de la Función Pública (1983-1986)}

La reforma de la Administración, por el contrario, era uno de los leit motiv o "mantras" del programa político del Partido Socialista Obrero Español (PSOE): era preciso reducir el poder patrimonializador de los cuerpos funcionariales tradicionales, fomentar la movilidad funcionarial independientemente de la adscripción corporativa tradicional, superar las plantillas orgánicas como mecanismos de adscripción de puestos a cuerpos, reducir y racionalizar el número de éstos, establecer la carrera administrativa, establecer un sistema de incompatibilidades... Con carácter inmediato, tras la formación del primer gobierno constituido después de las elecciones de finales de 1982 que le dieron la victoria, los trabajos para llevarla a cabo comenzaron con el protagonismo del Ministerio de la Presidencia ${ }^{33}$, partiendo de la premisa que “reforma" era, básicamente, sinónimo de "aprobación de nuevas leyes". Así, en 1984 y 1985 se aprobaron dos leyes ${ }^{34}$ de alto significado para aquella: la Ley 30/1984 de

32 Ver un relato detallado en Luis Fernando Crespo Montes, "La Función Pública española 19761986: De la transición al cambio" INAP, Madrid, 2001. En esta misma obra se contiene una crónica minuciosa y documentada de los detalles de las reformas 1983-1986.

33 Este protagonismo no fue absoluto en la medida en que la intención de sus responsables de hacerse cargo de las competencias en materia retributiva -competencia clave para llevar a cabo una política de organización e incentivos que acompañara al resto de las medidas- contó con la tajante oposición a ceder dicha competencia por parte del Ministerio de Economía y Hacienda que impidió la tramitación de un proyecto de decreto-ley redactado en tal sentido. Lamentablemente, la falta de sintonía entre ambos ministerios sería ya una constante durante todos los procesos de cambio en el seno de la Administración Pública, lo que por otra parte venía sucediendo desde la reforma tecnocrática de los años ‘ 60 .

4434 Previamente, y con un carácter altamente simbólico, al ser la primera, se había aprobado la Ley 25/1983 de Incompatibilidades de altos cargos, que ya anunciaba el camino de mayor rigor que se iba a se- 
Medidas para la Reforma de la Función Pública ${ }^{35}$, en cuyo proceso de elaboración negociada y de tramitación parlamentaria algunas de las propuestas iniciales que contenía fueron suavizadas o desaparecieron, y la Ley 53/1984 de Incompatibilidades del personal al servicio de las Administraciones Públicas, en cuya tramitación parlamentaria apenas se hicieron concesiones a la oposición dada la amplia mayoría parlamentaria de que se disfrutaba y del carácter emblemático del proyecto que desde el primer momento, y también en el curso de su aplicación una vez hecho ley, contó con el apoyo incondicional del Vicepresidente del Gobierno, Alfonso Guerra.

Este paquete normativo, su significado y consecuencias han sido analizados desde la perspectiva del análisis de políticas públicas:

"El primero [la Ley de Medidas] reflejaba algunos de los contrapuestos intereses en juego: el sistema de cuerpos iba a coexistir con un nuevo sistema de clasificación de puestos para la selección y la promoción y un régimen contractual no funcionarial fue establecido para los empleados públicos el cual iba a coexistir con el régimen estatutario. Por último regulaba el desempeño de múltiples puestos por políticos, nombramientos políticos de alto nivel, y funcionarios.

Sin embargo, el proceso de implementación de estas medidas legislativas fue solo parcialmente realizado. La implementación de la ley de incompatibilidades fue exitosa. En un momento de profunda crisis económica, con cambios en la política económica y con el inicio de profundas reformas sectoriales (como la reconversión industrial, la cual inicialmente agudizó el problema del paro) la eliminación del desempeño múltiple de puestos por funcionarios en los sectores público y privado fue una medida bien recibida. Por contraste, la ley de reforma de la función pública no fue inmediatamente implementada en toda su extensión. En orden a poner sus previsiones en práctica era necesario del desarrollo adicional de instrumentos de gestión que no solo requerían mucho tiempo sino que también eran muy polémicos. "36

Pese a la positiva valoración social que la autora citada hace de la normativa de incompatibilidades tampoco ésta estuvo exenta internamente de conflictividad en su aplicación, la presentación de un recurso de inconstitucionalidad frente a la misma y, especialmente, en el ámbito sanitario la "insumisión civil” propugnada por la cúpula de la Organización Medica Colegial, hicieron que su aplicación fuera muy gradual y cuidada con el fin de que la judicialización de la misma no frustrara el logro de los objetivos planteados de búsqueda de la eficacia y moralización del servicio público ${ }^{37}$.

guir en la materia, contrastando así con la permisividad tradicional existente hasta ese momento.

35 Inicialmente fue denominada en fase de anteproyecto "Ley de medidas urgentes para la reforma (...)" ya que se contaba con aprobar posteriormente un Estatuto de la Función Pública; desaparecido el adjetivo "urgente" la Ley se configuró con perspectivas de mayor estabilidad y el Estatuto no vio la luz hasta que en 2007, veintitrés años más tarde, se promulgó el Estatuto Básico del Empleado Público.

36 Raquel Gallego, "Public management policymaking in Spain1982-1996: Policy entrepreneurship and (in)opportunity windows" International Public Management Journal, CH, 2003 [traducción de JV].

37 Luis F. Crespo, op.cit. 
En cualquier caso, el impulso de este proceso normativo de reforma de la función pública se completó a finales de 1985 con la implantación de un nuevo sistema retributivo fundado en las características del puesto de trabajo desempeñado y no en la pertenencia a un cuerpo funcionarial. En palabras de un alto responsable político del momento en la materia, se trataba de "cobrar por lo que se hace y no por lo que se es". El diseño de este sistema corrió a cargo del Ministerio de Economía y Hacienda ${ }^{38}$ y su resultado tuvo tantos partidarios como detractores en función del resultado de la valoración de los distintos puestos de trabajo y del acuerdo o desacuerdo con los criterios de valoración de los puestos que, obvia e inevitablemente, de hecho, favorecían a unos y perjudicaban a otros o favorecían a unos más que a otros ${ }^{39}$. Uno de los factores que favorecieron la implantación del nuevo modelo fue que se llevó a cabo mediante un incremento del gasto, es decir ganancia para todos (aunque fuera irregularmente distribuida) habiéndose partido del principio de que la reducción de costes o el coste cero no estaban contemplados en modo alguno.

Tras estas realizaciones, la reforma de la función pública, concebida como proceso de elaboración de normas clave, perdió el impulso inicial bien fuera porque se considerara que había llegado al límite de las posibilidades que la realidad permitía habida cuenta de los distintos intereses en juego, bien fuera porque se perdiera interés por llevar a cabo transformaciones de otro tipo más allá de las reguladoras de la función pública entre las cuales solamente cabe citar la introducción del presupuesto por programas llevado a cabo en 1984, si bien los analistas especializados consideran que inicialmente se trató de "un formalismo sin un impacto destacable en la gestión pública-en las normas y rutinas de la actividad en la administración pública" ${ }^{40}$.

\section{La Modernización de la Administración (1986-1993)}

La siguiente etapa en el largo proceso de cambio de la Administración General del Estado comenzó a mediados de 1986 con la remodelación gubernamental acometida por el Presidente del Gobierno en la que se creó el Ministerio de Administraciones Públicas. Éste tenía dos objetivos políticos: en primer lugar lograr la culminación del proceso de transformación de España en un Estado Autonómico, altamente descentralizado política y administrativamente y, en segundo término, dar un nuevo impulso a la reforma de la Administración, materia está en la que, independientemente de los cambios normativos y de modelo de función pública llevados a cabo en la legislatura anterior, se consideraba que existía un amplio camino por recorrer.

A semejanza de lo sucedido en 1983, cuando el PSOE estaba recién llegado al Gobierno, los responsables del nuevo ministerio intentaron hacerse con la competen-

38 Ver Nota 33.

39 Raquel Gallego. "management instruments that were(...) very controversial" (op.cit).

40 Raquel Gallego, VII Congreso Internacional del CLAD sobre la reforma del Estado y de la Admi46 nistración Pública. Lisboa, 2002. 
cia relativa a las retribuciones y a las plantillas funcionariales para poder apoyar sus propuestas organizativas y de funcionamiento con una política presupuestaria. Como en la ocasión anterior, la oposición del Ministerio de Economía y Hacienda fue frontal, alegándose que los intereses permanentes de control del gasto desaconsejaban que el Ministerio de Economía y Hacienda perdiera esa competencia en favor de un departamento de carácter "circunstancial" [sic]. No obstante, probablemente como prueba de que la mejora de la Administración todavía seguía en la agenda política al máximo nivel, el Ministerio de Administraciones Públicas logró, al menos, incorporarse a los órganos colegiados que tomaban las decisiones en materia de retribuciones y efectivos.

Pese a este contratiempo, que resultó duro de aceptar, los trabajos comenzaron y en esta ocasión la estrategia escogida no fue la del cambio normativo. La polémica que las normas anteriormente promulgadas habían desatado, incluida la presentación de recursos ante el Tribunal Constitucional -estimado por éste, parcialmente, en sentencia de 1987, el planteado frente a la Ley de Medidas para la Reforma de la Función Pública en lo concerniente al desempeño de puestos de trabajo de la Administración por personal no funcionario, y rechazado en su totalidad en 1989 el concerniente a la Ley de Incompatibilidades- motivó que se buscaran otras líneas de actuación. Se optó, como alternativa, por la estrategia basada en la reflexión y en la construcción de un sólido discurso relativo a la necesidad de proceder a una transformación del funcionamiento de la Administración. Mejorar la eficacia de la acción administrativa, lograr la agilidad en los procedimientos, incrementar la receptividad y la transparencia en el comportamiento con los administrados, junto con el establecimiento de una carrera funcionarial todavía pendiente fueron los objetivos que se plantearon ${ }^{41}$. Una parte importante de la inspiración se encontró en los informes del Public Management Committee de la OCDE que recogían las mejores practicas de los países miembros de la organización en este campo, otra fuente de ideas surgió de las experiencias de trabajo compartidas con empresas privadas especializadas en el terreno de la consultoría de organización, procedimientos y auditoría de gestión, que aportaron “know how" para la Administración lo que permitió al grupo de funcionarios encargado de esta tarea el aprendizaje de técnicas punteras en estos ámbitos.

La introducción en el discurso de nuevos paradigmas como el paso del concepto de "administrado" al de "cliente" para referirse a los ciudadanos que pagan mediante los impuestos los servicios que reciben, lo que hoy es considerado normal por cualquier funcionario, en aquel momento constituyó una novedad que a algunos les resultaba herética42. La necesidad de impulsar un cambio en la "cultura administrativa"

41 Raquel Gallego, hacer eferencia a una entrevista que, para la realización del trabajo citado (Nota 36), mantuvo con unos de los directores generales del MAP. En ella éste le manifestó, en relación con este cambio de estrategia, que tras mantener el equipo directivo del MAP una reunión con el nuevo Ministro "convoqué a mis subdirectores generales y les dije: 'Mirad, vamos a empezar desde cero. Los objetivos establecidos por el Ministro no tienen nada que ver con lo que hemos estado haciendo hasta ahora' ".

42 En el curso de una reunión de la cúpula del MAP con el conjunto de los Secretarios de Estado y Subsecretarios uno de estos últimos planteó la que podríamos denominar "duda socrática" de a quién 
para orientarla, además de hacia el principio de legalidad, hacia los resultados, la innovación, la responsabilidad y la transparencia fue otro de los elementos clave del proceso de cambio que se propuso. Asimismo se introdujeron y difundieron desde el Ministerio de Administraciones Públicas ${ }^{43}$ técnicas de dirección y organización comunes en la empresa privada como la Dirección por Objetivos, previa adaptación a las peculiaridades de la Administración. También se estudiaron experiencias extranjeras como los "scrutinies" británicos que el gobierno conservador de Margaret Thatcher había puesto en práctica para optimizar el funcionamiento de las organizaciones administrativas del Reino Unido y suprimir las que se consideraran no necesarias en aplicación de su estrategia de "reducción de lo público".

En una estrategia de difusión en círculos concéntricos, la cúpula del Ministerio de Administraciones Públicas mantuvo largas y numerosas sesiones monográficas de trabajo con el conjunto de Secretarios de Estado y Subsecretarios, Delegados del Gobierno y una gran parte de los altos cargos de la Administración para difundir el nuevo discurso y las nuevas propuestas y contrastarlos con la realidad y con la cultura dominante entre los responsables de la dirección política y administrativa de la Administración General del Estado. En paralelo se pusieron en marcha "experiencias piloto" para aplicar los nuevos modos de organización y funcionamiento en los centros directivos que voluntariamente de incorporaban al proceso.

Como consecuencia de todo ello, tras tres años de trabajo, cuando se consideró cristalizada la situación, el Ministerio de Administraciones Públicas publicó el documento "Reflexiones para la Modernización de la Administración de Estado" 44 que recogía el conjunto de sus propuestas de cambio y lo apoyó con otros documentos y trabajos entre los que cabe destacar el "Estudio Dephi para la mejora de los procedimientos en la Administración Pública", un estudio prospectivo sobre las tendencias percibidas por más de trescientos directivos de la Administración General del Estado, y un Manual de estilo del lenguaje administrativo cuyo objetivo era hacer más comprensible para los ciudadanos el contenido de los escritos que la Administración les dirigía 45 .

[En el gráfico que sigue a continuación se recoge la secuencia temporal de los diferentes procesos que se analizan en este epígrafe, expresando también el agente que los promovió. Los dos últimos figuran en distinto color porque, como se dice en

\footnotetext{
debía considerarse "cliente" en el caso de los internos recluidos en un centro penitenciario, si al interno mismo o a los ciudadanos a proteger de sus acciones delictivas.

43 Técnicas gerenciales en la Administración. Monográfico de la Revista "Documentación Administrativa" n² 223, INAP, Madrid, 1990.

44 Ministerio de Administraciones Públicas, Madrid, 1990.

45 El "Estudio Delphi" mereció los elogios tanto de la prensa general como de la económica especializada (La Gaceta de los Negocios, 6 de julio de 1990, La actualidad Económica” n 1.687, octubre 1990); otro tanto sucedió con el Manual de estilo del lenguaje administrativo, que fue objeto de un elogioso edito48 rial del diario El País, el 21 de junio de 1990, que calificaba la iniciativa de mejorar la transparencia de la Administración como "hecho sin precedentes en la vida pública española".
} 
el texto, no tuvieron la entidad suficiente para considerarlos procesos de reforma. Por el contrario, el primero de ellos, aunque no llegara a buen término, se incluye con los que sí tuvieron ese carácter por dos razones: la primera porque sus promotores así lo percibieron y la segunda por su carácter simbólico de intento de reforma de la Administración de la dictadura]

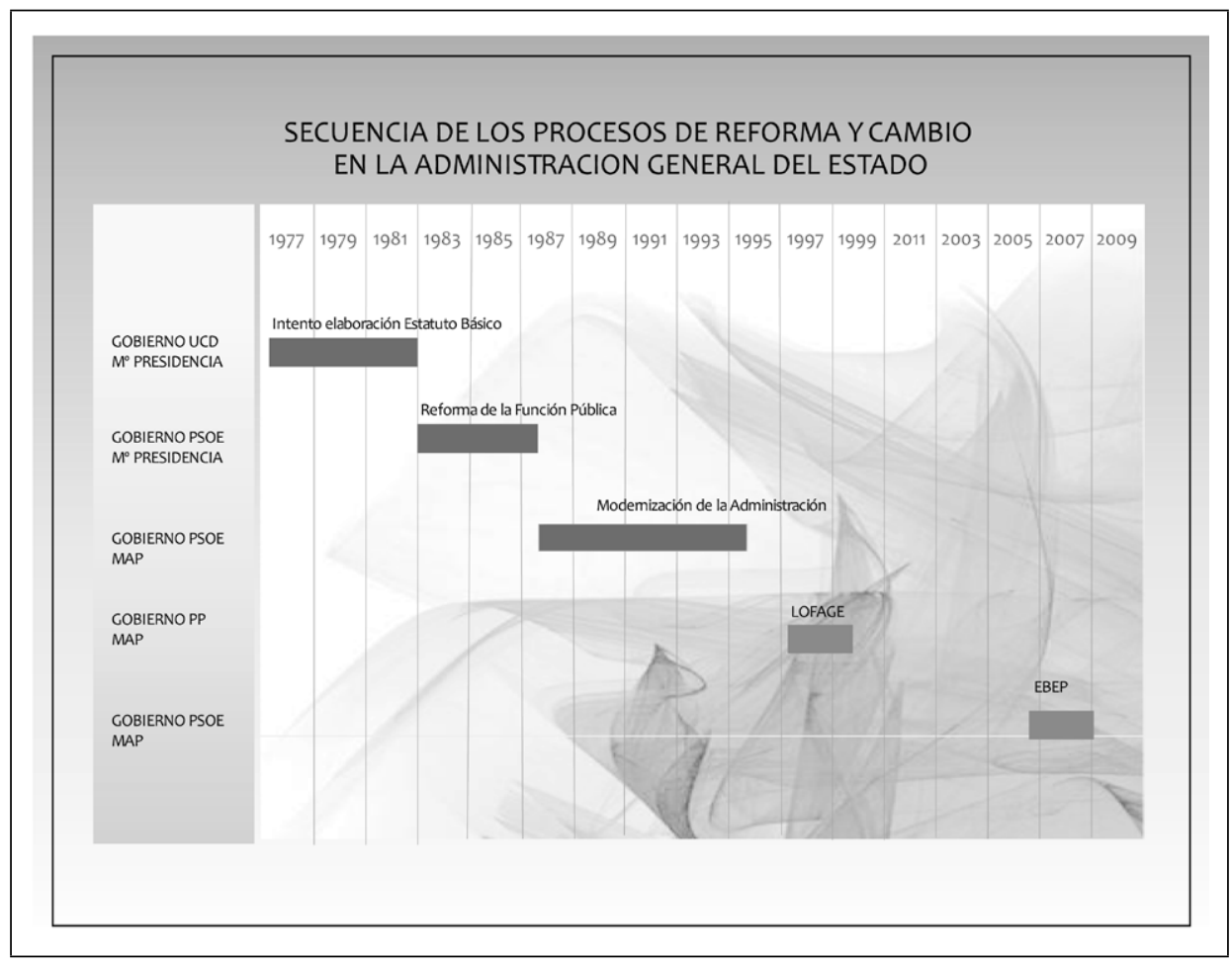

Todo ello, reflexiones, discurso, estrategias de cambio, aplicación de técnicas gerenciales, necesidad de llevar a cabo un cambio de cultura administrativa... llegó a calar como una lluvia fina en la Administración de aquellos años y se lograron importantes mejoras en algunas áreas. Sin embargo, la falta de impulso político en el vértice de la pirámide, a causa de la ausencia de implicación del Ministerio de Economía y Hacienda, que consideraba el proceso como una iniciativa exclusiva del Ministerio de Administraciones Públicas, impidió que el proceso alcanzara dimensión global. Por su parte, el Ministerio de Economía y Hacienda, siguiendo la misma lógica y principios inspiradores, pero actuando autónomamente al margen del proceso que se pretendía general, creó la Agencia Estatal de Administración Tributaria en 1991 dotándola de responsabilidad, autonomía en la gestión, recursos económicos dirigidos a potenciar la generalización de las Tecnologías de la Información y las Comunicaciones, etc. El resultado podemos verlo hoy ya que la AEAT se ha convertido en una de las organizaciones más eficaces y modernas de la Administración General del 
Estado con una mejor aceptación por parte de los ciudadanos en lo que se refiere al servicio prestado a los mismos y una alta valoración internacional entre los servicios homólogos.

Una nueva reorganización del Gobierno en febrero de 1991 conllevó el cambio de parte de los responsables del proceso en el Ministerio de Administraciones Públicas pero aún así se logró que en 1992 el Consejo de Ministros aprobara un Plan para la Modernización de la Administración del Estado, si bien su ejecución y una segunda edición del mismo ya tuvieron un carácter más formal que real conforme la atención política del Ministerio se centraba en el aspecto autonómico.

Como ha señalado Raquel Gallego para concluir el análisis de esta fase de la modernización de la Administración:

"Cualquiera que sea la interpretación sobre la creación del MAP a la que se dé más énfasis, se pensaba que la reforma administrativa era un difícil, complejo y polémico proceso cuyos resultados eran a tan a largo término como escasos eran sus beneficios políticos inmediatos" ${ }^{\prime 4}$.

\section{La Ley de Organización y Funcionamiento de la Administración General del Estado 1996-2000}

El acceso del Partido Popular al Gobierno tras las elecciones generales de marzo de 1996 contemplaba también llevar a cabo una reforma de la Administración, de nuevo mediante la estrategia de la reforma legal. Los puntos clave de la misma eran " adecuar su estructura y funcionamiento al diseño del régimen de Administración Única que evite duplicidades encarecimiento y confusión" y las tradicionales referencias a la neutralidad política, profesionalización, diseño de una carrera administrativa, etc. que se incluirían en un futuro Estatuto de la Función Pública.

Lo primero se llevó a cabo abandonando desde el primer momento de la redacción del anteproyecto el principio de Administración Única y por tanto la puesta en práctica de sus consecuencias organizativas, quedando aquella como elemento residual de reflexiones académicas en un ámbito muy reducido ${ }^{47}$, mediante la aprobación de la Ley 6/1997 de 14 de abril, de Organización y Funcionamiento de la Administración General del Estado (LOFAGE) para lo que se retomó el texto en el que se había estado trabajando en el Ministerio de Administraciones Públicas en los últimos dos años de la legislatura previa, que se había presentado por el Gobierno como proyecto de ley pero que había decaído al finalizar anticipadamente la legislatura.

46 Raquel Gallego, "Public management policymaking in Spain1982-1996: Policy entrepreneurship and (in)opportunity windows" International Public Management Journal, CH, 2003 [traducción de JV].

47 La Exposición de motivos de la Ley como concesión al planteamiento inicial se refiere a "la Administración única o común (...) de forma que el protagonismo administrativo en el territorio autonómico lo tenga la Administración autonómica" pero sin que el articulado contenga disposición alguna en tal línea. 
Se introdujeron en el texto preexistente importantes novedades como la supresión de los Gobernadores civiles y su sustitución por Subdelegados del Gobierno de carácter funcionarial ${ }^{48}$ y la integración de los servicios periféricos de los ministerios en las Delegaciones del Gobierno. Se incluyó asimismo en la LOFAGE, en la línea de “profesionalizar la Administración”, la previsión de que los directores generales fueran nombrados necesariamente entre quienes tuvieran la condición funcionarial ${ }^{49}$, salvo que razones organizativas debidamente justificadas e incluidas en los decretos de estructura de los departamentos ministeriales establecieran la posibilidad de poder nombrar a personas ajenas a las administraciones públicas. En la práctica esto supuso que el ochenta por ciento de los directores generales tengan la condición de funcionarios, cifra que es muy similar a la existente con anterioridad a esta previsión legal porque la mera práctica administrativa había llevado desde los primeros años 80 a que la selección de directores generales se hiciera entre los funcionarios habitualmente conocedores del sistema.

En segundo término, en cuanto a la normativa funcionarial, el Ministerio de Administraciones Públicas elaboró un anteproyecto de Estatuto Básico de la Función Pública que el Gobierno remitió en 1999 a las Cortes Generales. El proceso de negociación con las CC.AA, dado el carácter básico del proyecto, y la existencia de un pacto de gobernabilidad con Convergencia i Unió y con el Partido Nacionalista Vasco obligaron, según han manifestado los responsables de aquel proceso, a "adelgazar" notablemente la exhaustividad regulatoria del texto del que se partía y a delegar en los desarrollos posteriores buena parte de los contenidos sustantivos del proyecto (ordenación profesional, directivos... ) con excepción del capítulo dedicado a las relaciones laborales, en el que los sindicatos exigieron, para dar su conformidad al anteproyecto, una minuciosidad impropia en el contexto general del proyecto, antes descrito. En ese capítulo se detallaban los créditos horarios, derechos sindicales, órganos de representación, procedimientos de participación y negociación, etc. Flagrante contraste con el resto de políticas sustantivas que quedaban meramente apuntadas. Pero el proyecto, una vez remitido al Parlamento, quedó estancado desde un principio sin ver la luz como consecuencia de la imposibilidad de obtener el acuerdo de los grupos parlamentarios (especialmente el socialista).

En la siguiente legislatura 2000-2004 ya no se insistió en el proyecto puesto que la decisión del PSOE en el sentido de que iniciativas de ese carácter no prosperaran

48 La supresión de los Gobernadores Civiles constituyó una exigencia de la coalición nacionalista catalana Convergencia i Unió para dar su apoyo al nuevo Gobierno. En la tramitación parlamentaria del proyecto de ley, y en la línea de intentar minimizar la representación del Gobierno de la Nación en la periferia, su grupo parlamentario presentó una enmienda, que no fue aceptada, a fin de establecer que los Subdelegados del Gobierno tuvieran, como máximo, nivel de complemento de destino 28, persiguiendo excluirlos así no solo de la consideración de altos cargos de la AGE sino también de la categoría funcionarial mas alta, el nivel 30, propia de los subdirectores generales.

49 El requisito, que permanece, es efectuar los nombramientos, salvo excepciones que deberán ser justificadas reglamentariamente, entre funcionarios de carrera del Estado, de las Comunidades Autónomas o de las Entidades locales del Grupo A1. 
había sido claramente adoptada, para dicho Partido era demasiado que en su primera legislatura el nuevo gobierno del PP hubiera logrado aprobar la Ley del Gobierno, la LOFAGE y hubiera enviado a las Cortes el Proyecto de Estatuto Básico de la Función Pública; la conclusión era que no se podían apoyar más logros populares en esta materia.

\section{El Estatuto Básico del Empleado Público de 2007}

Si la promulgación de la LOFAGE no constituyó, en el sentido estricto de la expresión, una "reforma de la Administración" por su limitado alcance al ámbito organizativo, tampoco puede calificarse de tal, ni sus promotores lo presentaron nunca así, la nueva ley aprobada en 2007, ya de nuevo con un gobierno del PSOE surgido de las elecciones generales de 2004, bajo la denominación de Estatuto Básico del Empleado Público.

La Ley $7 / 2007$, de 12 de abril, se elaboró tras un amplio proceso deliberativo de un año, para recoger aportaciones e ir logrando zonas de acuerdo con los distintos sectores implicados e interesados, que contó con la participación de expertos de la propia Administración General del Estado, de las Comunidades Autónomas, de la Universidad, y tras la pertinente ronda de negociaciones con las organizaciones sindicales.

El EBEP proporciona un marco común, ciertamente amplio y con un importante margen de regulación propia al conjunto de las administraciones públicas y tiene entre sus principales novedades, aunque breve, una regulación de los directivos públicos que las distintas administraciones públicas pueden desarrollar de acuerdo con sus peculiaridades. Este asunto, pendiente desde décadas atrás, por cierto, fue insistentemente ${ }^{50}$ rechazado por parte de las organizaciones sindicales más representativas en la ronda de negociaciones mantenida con ellos ${ }^{51}$. Estas organizaciones sindicales, de

50 Con posterioridad a que los sindicatos hubieran dado su conformidad al anteproyecto, actuando en contra de dicho acuerdo CC.OO. promovió que en el trámite parlamentario, Izquierda Unida, procediendo como correa de transmisión inversa, propusiera, infructuosamente, la supresión del artículo 13 del Proyecto del Ley que se refería a los directivos.

51 La necesidad de negociar estas normas con las organizaciones sindicales más representativas parece estar en la lógica de las cosas. Si se trata de regular el régimen básico de los empleados públicos resulta imprescindible una consulta y negociación con las organizaciones que tienen atribuida su representación. Hasta tal punto esto es así que, salvo en casos de amplia mayoría absoluta, un proyecto de estas características tiene dificultades para ser aceptado por el grupo parlamentario que apoya al Gobierno para su tramitación en las Cortes si no cuenta al menos con la neutralidad de las organizaciones sindicales. La paradoja se produce cuando para lograr el apoyo al proyecto o, al menos, la neutralidad deben hacerse concesiones a dichas organizaciones que no redundan en beneficio de los representados sino en las cuotas de poder de las propias organizaciones. Así por ejemplo, cuando en 1996 se atribuyó una mayor representatividad a unas organizaciones en detrimento de otras al acordarse una composición de la Mesa General que beneficia extraordinariamente a las organizaciones mayoritarias (cuyo acuerdo interesaba para la negociación del EBEP) hasta el punto de que deja sin representación en la Mesa General al 45 por ciento de los votos emitidos en las elecciones sindicales (datos de la Dirección General de la Función Pública). Otra de las concesiones efectuadas se refiere al de número de horas de libre disposición para el ejercicio de actividades sindicales que luego 
acuerdo con los presuntos intereses de sus afiliados (personal laboral, de oficios varios, básicamente y, entre los funcionarios, aquellos de los niveles de menor cualificación profesional) no tenían ningún interés en que se regulara la existencia de un estrato directivo en la Administración Pública. Se trataba en este caso no solo de una manifiesta negación de la realidad (es evidente que alguien dirige la Administración para transformar en resultados concretos los objetivos establecidos por los responsables políticos tras cada proceso electoral) sino también un olvido de los intereses generales de la organización; afortunadamente la claridad con que la representación del Ministerio de Administraciones Públicas veía la necesidad de regular esta materia, tras años de reivindicación por parte de quienes ejercen estas funciones y de ser sobradamente conocida la opinión de los expertos y de la doctrina acerca de dicha necesidad, mantuvo el texto del anteproyecto y existe un capítulo, aunque escueto, dedicado a los directivos que permitirá a las distintas administraciones regular esta función.

Otro punto que fue objeto de confrontación y que también se saldó con el mantenimiento de las posiciones de la Administración fue el relativo a la solicitud sindical de participación de sus organizaciones en los procesos de selección de funcionarios, a semejanza de lo ya se les había concedido anteriormente en el Convenio Único del personal laboral. Desde el análisis jurídico el asunto no dejaba lugar a dudas, los tribunales de oposiciones deben guiarse por los principios de la imparcialidad individual, la independencia y la profesionalidad para garantizar el cumplimiento de lo establecido en el articulo 103 de la Constitución Española en el sentido de que el acceso a la función pública se efectuará de acuerdo con los principios de igualdad, merito y capacidad. Y nada más lejos de todo ello que una organización sindical que, por definición, se constituye para defender no la igualdad de todos los individuos sino los intereses de sus afiliados. En el fondo de lo que se trataba era de obtener otra parcela más de poder en forma de "cogestión" mediante la participación en los procesos de selección. Como ya hemos dicho, la incorporación de estas organizaciones a los órganos de selección de funcionarios no se produjo y el texto del artículo en cuestión excluía expresamente de la composición de los mismos a las organizaciones sindicales. En el trámite parlamentario una interesada enmienda de Izquierda Unida ${ }^{52}$ propuso lo siguiente: "Ias organizaciones sindicales representativas podrán participar con efectos fiscalizadores en los órganos de selección. Su participación será con voz pero sin voto", lo que ya rizaba el rizo de la paradoja: los sindicatos con interés en que sus afiliados superaran los procesos selectivos iban a ser los responsables de fiscalizar la pureza del proceso ejerciendo el control de la actuación de los representantes de la Administración Pública responsables constitucionalmente de velar por la aplicación de los principios de igualdad, mérito y capacidad... Felizmente, semejante atropello no prosperó pero la redacción del texto se suavizó para que el rechazo de la participación de los sindicatos no fuera ma-

\footnotetext{
se traduce naturalmente en el número de liberados a tiempo completo, etc. etc. Así sucedió, por ejemplo, en el caso del EBEP cuando para lograr el acuerdo del los sindicatos al texto sin tener que ceder a sus pretensiones para estar presentes en los órganos de selección de funcionarios hubo que recurrir en el último momento a elevar el número de representantes sindicales existentes en las Juntas de Personal (art. 39).

52 Ver nota 50 sobre la violación por CC.OO. del principio "pacta sunt servanda".
} 
nifiesto (lo que abre una vía a la litigiosidad contencioso-administrativa, siempre de incierto resultado y por tanto siempre esperanzador para estas organizaciones) y el texto aprobado se refiere meramente a que "la pertenencia a los órganos de selección será siempre a título individual, no pudiendo ostentarse ésta en representación o por cuenta de nadie." 53.

En cualquier caso, el capítulo del anteproyecto dedicado a la negociación colectiva, representación y participación institucional tenía su origen en el anterior proceso de negociación del proyecto de Estatuto Básico de la Función Pública en 1997-99. En dicho proceso, según han manifestado protagonistas del mismo, durante la primera legislatura del Partido Popular, se hicieron importantes concesiones con el fin de obtener el acuerdo sindical para el conjunto del texto. Al no progresar parlamentariamente el proyecto, por la oposición del Grupo Socialista a la que ya hemos hecho referencia, y cuando ya en la primera legislatura del gobierno del Partido Socialista se iniciaron las conversaciones del nuevo proceso de negociación, las organizaciones sindicales manifestaron que aquellas concesiones obtenidas eran irrenunciables, lo que fue aceptado por los nuevos negociadores.

Pese a que hasta ese momento siempre se había hablado del "Estatuto de la Función Pública" en el anteproyecto se introdujo la regulación de los aspectos esenciales de la contratación laboral. Ésta había alcanzado un importante volumen en la AGE por la fragmentación de la organización tradicional en una pluralidad de organismos y entidades de diverso tipo y, especialmente, en el ámbito local. De ahí que la denominación de la norma se refiera al "empleado público", como expresión de la aproximación de los regímenes jurídicos, estatutario y laboral, aunque sin confundirlos. En cualquier caso, de acuerdo con la jurisprudencia del Tribunal Constitucional, los puestos de trabajo que impliquen el ejercicio de potestades públicas deberán ser desempeñados exclusivamente por funcionarios públicos, si bien se prevé que el personal laboral pueda desempeñar los puestos de trabajo que determinen las correspondientes leyes de la Función Pública de la AGE y de las CC.AA. que desarrollen el EBEP. De este modo se completa, de momento, el proceso de aproximación entre funcionarios y contratados laborales iniciado en la Ley de Medidas para la Reforma de la Función Pública de 1984 cuya falta de concreción, que podía devenir en amplitud, llevó al Tribunal Constitucional a declararlo inconstitucional y a ordenar la reforma del precepto correspondiente.

53 Miguel Sánchez Morón que desarrolló un importante papel como asesor en la elaboración del anteproyecto ha escrito ("Comentarios a la Ley del Estatuto Básico del Empleado Público", Edit. Lex Nova, Valladolid, 2007, pág. 408) sobre este punto lo siguiente: “ (...) los sindicatos que han apoyado en su conjunto el EBEP rechazaron desde un primer momento esa propuesta que, en virtud de tal rechazo, ha ido experimentando varias modificaciones durante la redacción del proyecto de Ley y su tramitación parlamentaria, hasta omitir cualquier referencia expresa a las organizaciones sindicales. Como Ulises en la cueva de Polifemo, los sindicatos han logrado sustituir su nombre por el de <Nadie>, también sin duda para escapar de una situación incomoda para sus intereses, con el resultado de cambiar una norma clara por otra ambigua. Ahora bien, el precepto, con la redacción que tiene, necesita de una interpretación. Y ésta no puede llevar sino a vedar la posibilidad de que organizaciones representativas de intereses de cualquier tipo nombre, designen o tengan $54 \quad$ la facultad de proponer miembros de los órganos de selección, pues si se les otorga ese poder se genera en realidad un vínculo de representación, aun no formalizado." 
Quedan pendientes para desarrollar en el futuro Estatuto del Empleado Público de la Administración General del Estado, por lo que a nosotros se refiere, aspectos tan importantes como el régimen de los directivos públicos y los detalles del sistema de selección (acertadamente, en el EBEP el simple concurso tiene carácter excepcional y debe ser establecido en cada caso mediante ley). Será ahí donde, como ha señalado una directiva especializada en la gestión de los Recursos Humanos, "se determine si se avanza en una Función Pública al servicio de los ciudadanos o sí, por el contrario, nos encaminamos a un sistema enmarañado donde los principios de eficiencia, igualdad y seguridad jurídica estén expuestos a males mayores." ${ }_{54}$.

\section{Ley de Agencias Estatales para la Mejora de los Servicios Públicos}

Con carácter previo, en esta misma legislatura el Ministerio de Administraciones Públicas promovió ante el Consejo de Ministros el Proyecto de Ley de Agencias Estatales para la Mejora de los Servicios Públicos que resultó aprobado por las Cortes Generales como Ley 28/2006, de 18 de julio. El origen de este proyecto estaba, como señalaba la Exposición de motivos de la Ley, en "las rigideces que presentan los actuales modelos de gestión y la escasa autonomía con que cuentan los organismos públicos, sobre todo en su configuración de organismos autónomos (...)"

El objetivo de esta nueva ley y de su producto, las Agencias, era dotar a la Administración General del Estado de una nueva figura organizativa de carácter general dotada de un adecuado nivel de autonomía y de flexibilidad en la gestión: "que los ciudadanos -decía la Exposición de motivos- puedan visualizar de manera clara cuáles son los fines de los distintos organismos públicos y los resultados de la gestión que se ha encargado a cada uno de ellos, así como la forma en que se responsabilizan sus gestores por el cumplimiento de los objetivos que previamente les han sido fijados de manera concreta y evaluable."

La iniciativa fue acogida con notable interés por aquellos organismos y centros directivos que estaban necesitados de las mencionadas autonomía y flexibilidad en la gestión y la propia Ley autorizó al Gobierno a crear diez agencias que se consideraron de urgentes. Sin embargo, la tradicional falta de concordancia entre el Ministerio de Administraciones Públicas y el de Economía y Hacienda a la que ya hemos hecho referencia anteriormente, acabó limitando el alcance de aquellos rasgos y posteriormente la creación de nuevas agencias que estaban en cartera se ha visto paralizada como consecuencia o al amparo de las medidas adoptadas para reducir el déficit público ${ }^{56}$.

54 Mercedes Rodríguez Arranz, "Comentario al Estatuto Básico" en Revista ACEs, editada por la Asociación Profesional de Administradores Civiles del Estado, Madrid, junio 2009.

55 Estas rigideces habían llevado en los últimos años a una proliferación de organismos (47 de un total de 138 organismos públicos) cada uno de ellos con su propia regulación que perseguía, al amparo de sus particularidades organizativas o sectoriales, gozar de una mayor autonomía con respecto a la AGE.

56 El Real Decreto 8/2010, de 20 de mayo, por el que adoptan medidas extraordinarias para la reducción del déficit público, establece en su Disposición adicional quinta. Creación de Agencias Estatales, lo 


\section{CONCLUSIONES}

$1^{\text {a }}$. El proceso de reforma llevado a cabo entre 1983 y 1985 estuvo centrado en la reforma de la función pública con evidentes repercusiones en su estatus jurídico y en determinados aspectos del funcionamiento de las organizaciones, en tanto que el de finales de los años 80 se centró más en el funcionamiento de los procedimientos y servicios y en la organización, realizando una reflexión y diagnóstico previos sobre la situación existente y las necesidades pero sin que finalmente sus propuestas de transformación de alcance tuvieran una materialización concreta más allá de algunos cambios en la cultura organizacional vigente.

Las posteriores modificaciones legales, respectivamente 1997 y 2006-07, han afectado tanto a aspectos organizativos como funcionariales pero sin una vocación transformadora de los aspectos esenciales del sistema.

$2^{a}$. Tras el proceso de descentralización política y administrativa que ha configurado nuestro Estado autonómico, la Administración General del Estado ya no es la que cuenta con el mayor número de efectivos (en 1982 aglutinaba el 82 por ciento del empleo público). Actualmente la Administración más amplia es la correspondiente a las Comunidades Autónomas que cuentan con el 52,6 por ciento del total, en tanto que la minoritaria es la Administración General del Estado con un residual 22,8 por ciento.

$3^{\mathrm{a}}$. Comparativamente con los países desarrollados, miembros de la Unión Europea o de la OCDE, España tiene un tamaño del sector público inferior a la media: un empleado público por cada 17,3 habitantes (2009) y un gasto público que supone el 38,5 por ciento del PIB (2006), en tanto que la media de la UE era del 46 por ciento. Como consecuencia del impacto de la crisis económica y su incidencia sobre el gasto social, este volumen de gasto se ha elevado en 2009 a un 49 por ciento del PIB, todavía inferior a la media tanto de la Zona Euro como al conjunto de la UE que también ha visto subir el volumen de su gasto público como consecuencia de la necesidad de desarrollar políticas específicas para hacer frente a la crisis económica global.

$4^{\mathrm{a}}$. Independientemente de lo anterior, la construcción del Estado autonómico en un periodo tan corto de tiempo, junto con indiscutibles beneficios para los ciudadanos ha tenido como efecto secundario la aparición de importantes duplicidades organizativas e ineficiencias que es preciso analizar para llevar a cabo los ajustes necesarios.

$5^{\mathrm{a}}$. El análisis de la distribución de efectivos en la Administración General del Estado muestra que solo el 2,8 por ciento del los funcionarios ocupan puestos de la mayor cualificación profesional y complejidad de desempeño (niveles 29 y 30 ) frente a un 74,4 por

siguiente: Se suspende lo dispuesto en la disposición adicional Trigésima primera de la Ley 26/2009, de 23 de diciembre, de Presupuestos Generales del Estado de tal forma que en 2010 no se autorizará la creación de ninguna nueva Agencia estatal de las reguladas en la Ley 28/2006, de 18 de julio, de Agencias estatales para la mejora de los servicios públicos. 
ciento que desempeña puestos de gestión material o administrativos. La pirámide de distribución de efectivos no es la apropiada para hacer frente a las necesidades actuales y, menos aún, futuras de la AGE. Los datos reflejan una grave desproporción interna, con escasez de efectivos para llevar a cabo tareas complejas como el análisis de políticas, la participación en las negociaciones de los órganos de la UE (con el imprescindible dominio de idiomas), el diseño de proyectos, el control y la evaluación de resultados, entre otras. De otra parte, se evidencia la existencia de un sobredimensionamiento de las plantillas en lo que se refiere a los efectivos destinados a llevar a cabo actividades de apoyo administrativo cuyo grueso ha sido transferido a las Comunidades Autónomas o han quedado superadas por la utilización de modernas tecnologías.

Lamentablemente, todo indica que como consecuencia de las medidas de congelación de la oferta de empleo público en los cuerpos del Grupo A1, adoptadas en el contexto de la reducción del déficit público, esta carencia de profesionales cualificados se va a acentuar en el próximo quinquenio.

Llevar a cabo una reflexión profunda sobre este aspecto concreto del dimensionamiento interno de los efectivos de la Administración General del Estado resulta imprescindible con el fin de establecer una adecuada estrategia de selección para atraer nuevos funcionarios acorde con las necesidades de aquella en el siglo XXI.

6. La percepción negativa que los ciudadanos tienen a priori del funcionamiento de la Administración mejora notablemente cuando se trata de los resultados concretos de su trato con ella, en cuyo caso prácticamente se dobla el grado de satisfacción superándose el 60 por ciento. Del mismo modo la valoración del servicio recibido supera ampliamente las expectativas existentes inicialmente.

En esta valoración positiva parece tener una importante influencia el impulso dado por la Administración General del Estado a la implantación de las Tecnologías de la Información y las Comunicaciones y especial y últimamente a la posibilidad de relacionarse a través de Internet, por incipiente que esta relación sea aún.

$7^{\mathrm{a}}$. Pese a la todavía baja utilización que tanto las personas como las empresas hacen de Internet cuando ello es voluntario, la vía tecnológica TIC se presenta claramente como una apuesta obligada de carácter intensivo, tarea en la que la Administración General del Estado aparece claramente más avanzada que las administraciones autonómicas y locales. La implantación plena de la Administración Electrónica como elemento que contribuya al desarrollo económico y social de España debe ser el objetivo para el próximo quinquenio dadas las necesidades económico-productivas y sociales existentes en el país y el alto grado de satisfacción que genera. Ello debe llevarse a cabo pese a las limitaciones presupuestarias que sin duda van a existir como consecuencia del contexto global.

$8^{\circ}$. La Administración pública no resiste la comparación con la empresa privada en lo que concierne a la percepción que los ciudadanos tienen de valores inspiradores como la eficacia, la responsabilidad, la calidad, la innovación... Si bien es cierto que 
las normas que regulan el funcionamiento de la Administración General del Estado con el fin de garantizar los principios de igualdad y el respeto a los derechos de los ciudadanos pueden suponer una dificultad en esta materia, es evidente la necesidad de llevar a cabo transformaciones profundas tanto en la cultura administrativa vigente como en los procesos de funcionamiento y, especialmente, en la orientación de las organizaciones hacia los resultados. Ello es especialmente importante si atendemos en que, pese a la valoración señalada, los ciudadanos no consideran en modo alguno que la solución sea la privatización de los servicios públicos.

$9^{\text {a. }}$ En la actualidad la iniciativa en marcha de mayor interés está constituida por la implantación de la Administración Electrónica, sin que se hayan identificado otros procesos transformadores relativos a la organización o a la función pública, algunas de cuyas carencias pueden verse agravadas como consecuencia de las medidas adoptadas al hilo de la necesidad de reducir el déficit público.

\section{CODA}

Algunos echarán de menos, probablemente con motivo, un análisis o al menos una referencia a los mecanismos que en estos años han mantenido a la Administración General del Estado a salvo de la penetración en su seno de las redes de corrupción, a diferencia de los que ha sucedido en numerosas corporaciones locales y comunidades autónomas.

La razón de tal ausencia en este trabajo radica en la complejidad de la materia y en la extensión que requeriría para tratarla con el adecuado rigor y podría ser objeto de análisis en el futuro. Pero no debemos dejar de señalar que, en nuestra opinión, la razón de la ausencia de tales niveles de corrupción política y funcionarial en la Administración General del Estado estriba en que esta se encuentra mucho mejor preparada que las demás administraciones para resistir las presiones de dichas redes gracias a la existencia de unos cuerpos funcionariales profesionales cuya selección se lleva a cabo con todo rigor para garantizar los principios constitucionales de igualdad, mérito y capacidad, lo que les concede la característica de la inamovilidad como garantía de la independencia e imparcialidad con que ejercen sus funciones públicas, independientemente del curso político que marcan los procesos electorales.

Tal característica, repetimos, existencia de cuerpos de funcionarios rigurosamente seleccionados e inamovibles, debe ser preservada en el futuro sin caer en la tentación de llevar a término cambios en los procesos de selección, encuadramiento y permanencia sugeridos por pretendidas mejoras en la agilidad, eficacia, etc. a imitación del sector privado, que podrían poner en peligro el modelo que es una constante de las sociedades económica y democráticamente avanzadas. 